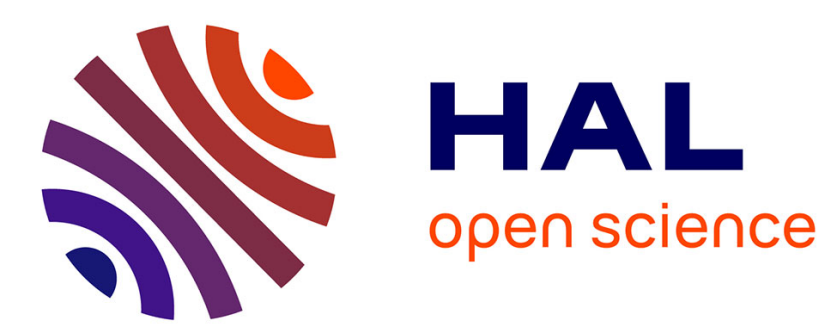

\title{
3D printing of mortar with continuous fibres: Principle, properties and potential for application
}

Jean-François Caron, Léo Demont, Nicolas Ducoulombier, Romain Mesnil

\section{To cite this version:}

Jean-François Caron, Léo Demont, Nicolas Ducoulombier, Romain Mesnil. 3D printing of mortar with continuous fibres: Principle, properties and potential for application. Automation in Construction, 2021, 129, pp.103806. 10.1016/j.autcon.2021.103806 . hal-03443519

\author{
HAL Id: hal-03443519 \\ https://hal.science/hal-03443519
}

Submitted on 2 Dec 2021

HAL is a multi-disciplinary open access archive for the deposit and dissemination of scientific research documents, whether they are published or not. The documents may come from teaching and research institutions in France or abroad, or from public or private research centers.
L'archive ouverte pluridisciplinaire HAL, est destinée au dépôt et à la diffusion de documents scientifiques de niveau recherche, publiés ou non, émanant des établissements d'enseignement et de recherche français ou étrangers, des laboratoires publics ou privés. 


\title{
3D printing of mortar with continuous fibers: principle, properties and potential for application
}

\author{
Jean-François Caron* Léo Demont* Nicolas Ducoulombier* \\ Romain Mesnil ${ }^{\dagger}$
}

December 2, 2021

\begin{abstract}
Important developments in additive manufacturing with concrete have been achieved in the past decades. Yet, printed components usually do not comply with building standards or basic reliability principles, and are not commonly used as load-bearing components. A gap between research and practice exists and despite several attempts, off-the-shelf commercial solutions for the reinforcement of the 3D printed structural components seem always expected. This article presents an alternative (pending for patent [8]) for reinforcement of 3D printed structures. This technology inspired by the composite industry is called Flow-Based Pultrusion for additive manufacturing (FBP). A strict control of the rheological behaviour of the cementitious matrix ensures the routing and impregnation of continuous rovings of thin fibres (glass, basalt, etc.) without any motorization. The resulting material, Anisotropic Concrete, homogeneously reinforced in a single direction, provides new possibilities, may enhance strength and ductility for hardened material but also help to a better handling of the fresh laces during the deposition, permitting inclined or cantilever paths. This paper describes the process, its constraints, first experimental achievements and first investigations about the mechanical performances of such a material.
\end{abstract}

keywords additive manufacturing; pultrusion; concrete printing; composite materials; fibre reinforced concrete; anisotropic concrete

\section{Introduction}

The cement industry contributes about $5 \%$ to global anthropogenic CO2 emissions [36. In [41, authors estimated in a very complete study, that total carbon

*Navier Laboratory, École des Ponts ParisTech, Univ. Gustave Eiffel, CNRS, Marne-LaVallée, France

†École des Ponts ParisTech, Marne-La-Vallée, France 
emissions from cement production in 1994 were 307 million metric tons of carbon (MtC), $160 \mathrm{MtC}$ from process carbon emissions, and $147 \mathrm{MtC}$ from energy use. In 2016, the estimation reached $1450 \mathrm{MtC}$ [3]! It's considerable and this drastic increase these last decades, due in part to the more recent Chinese con35 sumption, challenges to reduce the amount of cement. Of course, using other materials, as steel or wood may help to this aim. But the optimisation of concrete structure designs and implementing the right material at the right place is also necessary. Digital technologies, like large-scale 3d printing are a step in this direction because they allow for more complex structures, which have

40 a chance to be more sustainable. However, reinforcement of such structures is still a vastly open question.

Several reinforcement strategies have been proposed during the last century to improve the tensile strength and ductility of concrete. Metallic rebars are undoubtedly the most conventional reinforcement: they are cheap, optimised, and 45 easy to install. Rebars can carry the tensile forces thanks to a good anchorage in the concrete. They distribute stresses in the concrete favouring micro-cracks at the expense of disastrous macro cracks. Fibre-Reinforced Plastic rebars exist since the 1980's [29, 9] but remain anecdotal and devoted to very specific situations, due to a higher cost and lower stiffness. For example, their durability is 50 an asset when rapid internal corrosion of steel rebars is a problem [17.

But glass, carbon, basalt fibres may also be used directly (without polymer impregnation) as constituents of technical fabrics used in replacement of more rigid rebars 37. They are easier to handle and to shape (complex geometries), but also less efficient structurally as classical pouring techniques make it difficult to 55 obtain a good impregnation of rovings (gathering thousand of microfibres) and a good shear transfer in concrete. Short fibres mixed in the fresh concrete before pouring, like in Ultra-High-performance Fibre Reinforced Concretes (UHP FRC), are nowadays a classical and efficient solution and provide post-cracking behaviour. However, due to the necessary workability of the fresh mix, the fibre ${ }_{60}$ ratios remain low, around 1\%,2 or $3 \%$ are possible but represent a hard job to achieve on site. Many studies concern these topics, see for example [31 [22] and permit to link multicracking phenomena, pseudo strain-hardening behaviour, or increased ductility, to the type or volume-ratio of the fibers : discussed further in Section 4 .

${ }_{65}$ The pre-tensioning or post-tensioning of rebars or cables is also a technical solution that decreases the tensile stresses in the concrete, increasing thus the load-bearing capacity of the structure. Pre-stress is mainly used to connect prefabricated components of large structures like bridges. These components can be manufactured with 3D printing, as proposed in 23 or 39. However,

70 pre-stressing technology deals more at the structural scale than at the material scale, which is the focus of this article.

More specifically the purpose of this paper is to propose a solution to reinforce printed concrete itself. Some strategies already exist in this direction as well and have been reviewed in detail in [4 and very recently in [26] where a very 75 complete and generic classification and process description outline of different existing systems is proposed, and claimed by the authors as an extension of the 
RILEM process classification framework for Digital Fabrication with Concrete (DFC). Several proposals are revisiting classical reinforcement strategies mentioned earlier, using rebars or grids in combination with printed concrete. They are generally developed for non-standard concrete structures and as part of an integrated digital process based on sophisticated robotic fabrication strategies. Smart Dynamic Casting and mesh mould developed at ETH Zurich 24] propose a robotic concept which allows for the continuous production of a three dimensional welded reinforcement mesh used here as a formwork, and the concrete 85 infill. The technology is based on this porous cage ability to evacuate water excess. At the time of pouring, water contained in the concrete is instantly evacuated through the filtering faces, attenuating thus the hydrostatic pressure. Such sacrificial filtering formworks were first proposed for conventional concrete in France (Dipy 1992, 3DR 1999 38) and later in China 32. They permit 90 complex shapes and an attenuation of hydrostatic pressure by more than $80 \%$. The NEST building at Empa in Zurich implements some experimentations using new 3D printed concrete technologies for freeform columns and roofs, produced without formwork.

Some other proposals address the reinforcement of the extruded lace itself. In-

95 teresting experimentation based on an idea firstly presented in 21] consists of the driving of a reinforcement cable into the extruded concrete lace during printing [5]. Concrete beams have been printed and reinforced with such cables, and the results are encouraging, although the bond between the concrete and the steel cables needs to be improved to avoid the premature slippage observed by 100 authors.

Using a similar motorized device, the driving of a single MCF (Mineral-impregnated Carbon-Fiber) roving in the printed lace have been proposed in [27, thanks to a stationary impregnation line. Finally, the addition of short fibres in concrete is also widely investigated since it is an obvious solution. Like for FRC, fibres 105 improve rather the cracking behaviour even if an increase of the flexural tensile strength may be highlighted in the literature. Fibres are mixed before pumping and are thus homogeneously dispersed in the section. Their maximum ratio is limited to a few percent due to pumpability requirements [20] 30. Interestingly, the authors show that printing significantly aligns the fibres in the flow 110 direction. This leads to a homogeneous anisotropic behaviour of the reinforced lace, which could radically change the design of concrete structures, and lead to breakthrough innovations.

Our proposal, first introduced in 15 , fits in this context, allowing much higher fibre ratios and thus even greater anisotropy, due to a better alignment of long fibres. We called the process Flow-Based Pultrusion (FBP) and it is now a pending patented process for extrusion-based additive manufacturing of continuously reinforced mortars [8]. The principle is that continuous fiber rovings are impregnated and pulled by the mortar flow. A close process may be found at a smaller scale, with different materials and applications [25] for the fused120 deposition of polymers by 3D printing: the flow of a fused thermoplastic pull long carbon fibers. Here, an experimental devoted device including mortar extrusion and fiber's bobbins management is now developed. An intimate mix 
of fibres and matrix ensures the stresses transfer inside the resulting material, which can consequently be considered homogeneous, in the spirit of composite materials. The mixture modelling rules may apply, the framework of continuous mechanics becoming relevant for the estimation of homogeneous mechanical properties.

The process is described in the next part, more details concerning technological and rheological requirements and limitations, can be found in [10. Then the

130 potential for this technology will then be discussed, through experimentations on fresh laces and hardened specimens.

\section{Flow based pultrusion and anisotropic con- crete}

Adapted to a fully digital environment, the process includes the specific device for mortar extruding, for routing and management of fibers (prototype), a 6 degrees of freedom robotic arm (ABB), and a code permitting the global workflow (based on HAL Robotics software). The set permits to build a structure layer by layer through a continuous deposition of material, following a classical robotic path, but the fibering may also proposes more innovative investigations 140 as demonstrated in the second part of the paper. In this process, concrete rather refers to fine cementitious material, such as mortar or paste with a maximal particle size limited to few millimeters, for a good impregnation of the rovings. These continuous multi-fiber rovings are the reinforcement unit and made of mineral or organic fibres, such as Basalt fiber, AR glass fiber or carbon fiber.

145 Monofilaments as $0.1 \mathrm{~mm}$ steel wires were tried 14 but didn't demonstrate good results due in particular to a too smooth and regular fiber surface, leading to a poor interface quality with mortar. During the process, tens of these continuous rovings are continuously added to the cementitious mortar and pulled by the flow before final deposition. The obtained reinforcement ratio of the anisotropic 150 concrete, finally depends on the ratio of reinforcement in a transversal section of the lace. The first device permit ratio up to $1 \%$ (10 rovings), but a more industrial prototype is in progress and will permit higher ratios by adding more rovings.

\subsection{Extrusion Lace Shaping versus Oriented Lace Pressing}

A key point concerning robotic extrusion of concrete, from a material point of view, and without considering fibering, is the mastering of yield stress at nozzle exit and its evolution through time [35. This viscoplastic material has also a thixotropic behavior and many parameters must be controlled to allow the 160 deposition and the increasing weight of additional laces without buckling collapses. Different printing technologies are classically used, and they belong to 2 main families identified in [12, Extrusion Lace Shaping (ELS), and Oriented 
Lace Pressing (OLP).

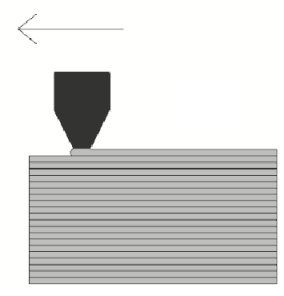

OLP

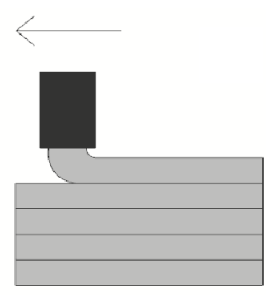

ELS

Figure 1: Illustration of ELS and OLP printing strategies, taken from 12.

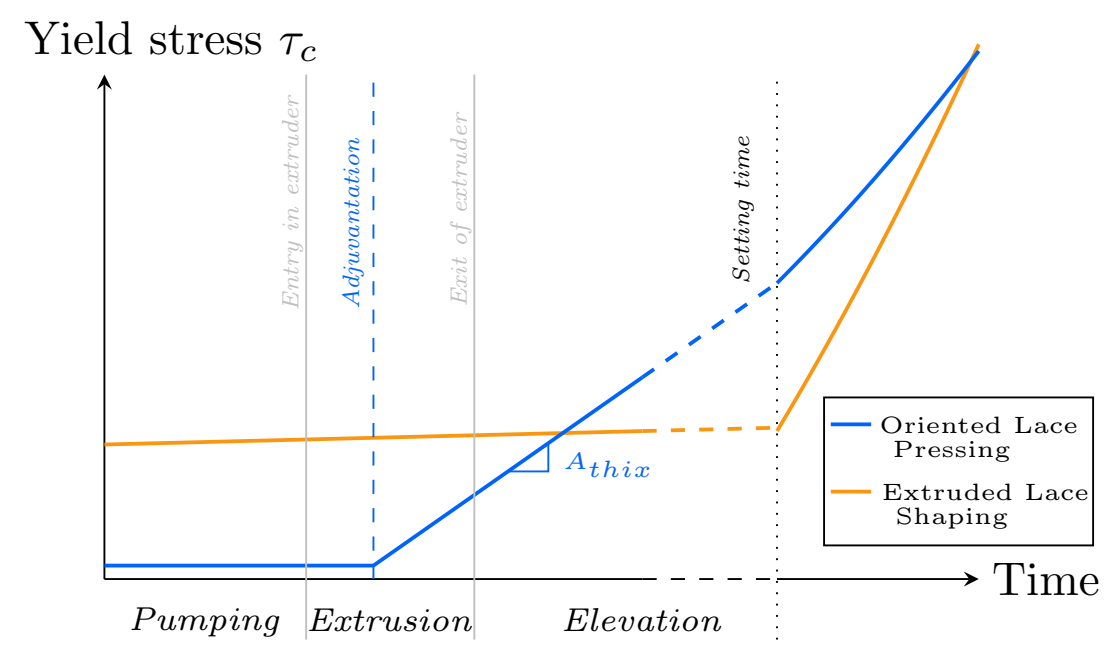

Figure 2: Structuration rate for both asymptotic regime, Extrusion Lace Shaping (ELS) and Oriented Lace Pressing (OLP).

ELS concerns firm material, with an initial yield stress well above thousands of pascal. During the extrusion, the filament section is prescribed by the nozzle shape, as shown in Figure 1. As a consequence, the section of the lace is not changed during deposition. Moreover, the large yield stress value ensures a strong consistency and an easy deposition of the first couple of layers. This refers 170 to the simplest printing technologies, such as the pioneering contour crafting process [21]. It is very efficient and reliable. But once the mix is realised, there is no way to modify the extruded material, neither to adapt at external modifications, nor to propose more sophisticated strategies. For instance, to permit a good impregnation of rovings, it is natural to think about a fluid 
composition, which has to harden very quickly to avoid the collapse of the printed lace stack. This shows all the interest of the other available technology, OLP. OLP is devoted to more fluid materials, i.e. for yield stress value around hundreds of pascals. In this case, the thickness of the layer is prescribed by the distance between the nozzle and the previous layer (see Figure 1) and its width

180 is given by the conservation of mass. If the width of the extruded lace is superior to the exit diameter of the nozzle, the plastic flow during deposition can induce a pressure peak, proportional to yield stress at the nozzle exit, which needs to be limited to prevent object failure [7. This regime is often found for high structuration rate material that is achievable using a more sophisticated printing technology. Indeed, the high structuration rate is provided by the addition of an accelerator additive or viscosity modifier additive (VMA) to the extruded material. A comparison of the evolution of the yield stress during the printing for ELS and OLP is illustrated in Figure 2 An example of such printing device is described in detail in [19. Thanks to this mastering of the time-dependent rheology of the mortar, OLP is consequently of great interest as may combine first a good impregnation of rovings and then a good mechanical behavior of the stacking of printed laces. OLP is consequently the technology used in our development.

\subsection{Flow-Based Pultrusion versus motorized devices}

The proposed Flow-Based Pultrusion (FBP) technology is then very similar to other OLP robotic extrusion technology. The only change is the addition of rovings in the concrete flow just before the nozzle exit. To ensure the driving of the rovings several strategies are possible concerning the application of the mechanical force needed on the roving. This mechanical work may be brought by

200 rollers, like in bi-extrusion and pultrusion, as defined in Figure 3. In our present FBP solution, the mechanical work is provided directly by the shear interaction between the concrete flow and the rovings. The geometry of this nozzle and the adjustable rheological conditions have to ensure enough pulling force on the rovings to drive the reinforcement. A longitudinal principle cut of this nozzle is 205 also illustrated in Figure 3 . The evolution of the uniaxial forces applied on the reinforcements during deposition, are also plotted for each process. It is really important to notice that internal force is only in tension for traditional and flowbased pultrusion. On the contrary, pushing force is applied in the co-extrusion process which leads to compressive internal force. This compressive force could 210 limit the minimal radius of the continuous reinforcement unit to avoid buckling issues, and consequently limit also the curvature of the printing path, due to the higher flexural rigidity of a larger roving. Moreover, reinforcement rovings with smaller diameters increase the specific surface area of reinforcement and consequently the interaction with concrete. This aspect is further discussed in

215 the next subsection. Another point is that during a curved path, the inside bend roving, must have a smaller deposition speed than the outside bend one. As a consequence, co-extrusion of more than one roving becomes very difficult for a curved printing path, since reinforcement deposition is made by controlling 
the speed. This is not the case with FBP, where the deposition of the roving is controlled by a shear force. The modification of the concrete flows inside the nozzle is expected to play the role of a differential gear.

All this indicates the importance of mastering the concrete rheology : it is
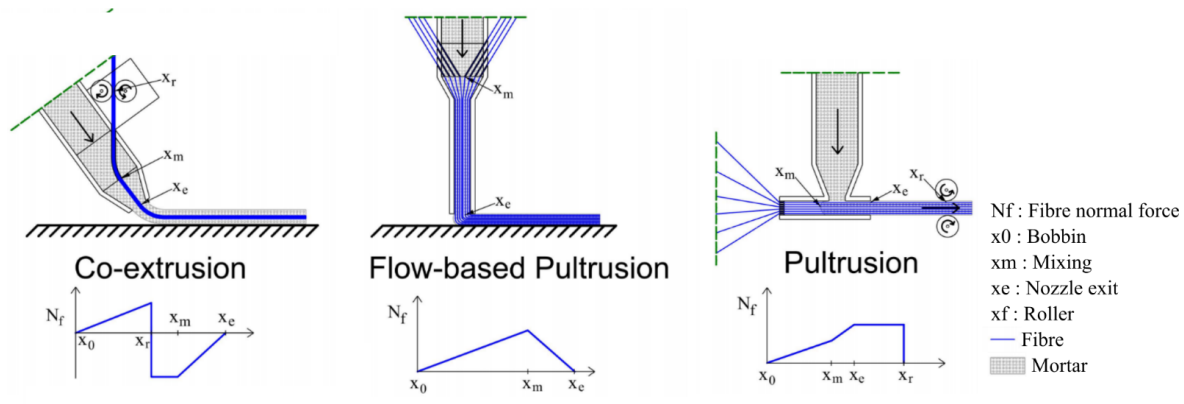

Figure 3: Schema of different continuous reinforcement processes (from [15])

a key point of the technology. Numerous conditions exist on the rheology of the concrete during robotic extrusion. They mainly refer to three macroscopic properties of the mortar, well studied in the scientific literature, pumpability, extrudability, and buildability. Here it is important also to be able to estimate the ability to generate a given pulling force on the continuous reinforcement roving. To do so, a simple analysis is proposed using the hypothesis that maximal interfacial shear stress between roving and mortar is equal to the yield stress $\tau_{c}(x)$ of the mortar. Under this condition, the maximal pulling force applied on each roving with no relative displacement between fibre and mortar, noted $F_{\max }$ is given by the integration of the equilibrium of an element of the roving and is equal to:

$$
F_{\text {max }}=\int_{x_{m}}^{x_{e}} \tau_{c}(x) P \mathrm{~d} x
$$

with $P$ the cumulated perimeter of each fibers of the roving, $x_{e}$ the location of nozzle exit and $x_{m}$ the location of mixing, defined in Figure 3 . For a constant yield stress, between mixing and nozzle exit, it gives:

$$
F_{\max }=\tau_{c} P l
$$

with $l=x_{e}-x_{m}$ the roving-carrying length (see 3). But such a mortar is 235 not the better choice to allow a good impregnation, since the yield stress is constant and must be high to permit the driving of the roving. Mortars with a high structuration rate, permitting a fast increase of the yield stress are more promising. This structuration can be supposed linear with time, as proposed in [33, and another expression for $F_{\max }$ using Equation 1 can be found. The yield 240 stress before starting the process and at the nozzle exit have to be measured. On our actual device, the order of magnitude of the necessary force to apply on 
a roving to fight against various frictions due to the wire conveyor is 0.1 Newton. The global perimeter of the reinforcement roving is about $1 \mathrm{~mm}$ and the length of the carrying zone is $100 \mathrm{~mm}$. Under that condition, the mean value of the yield stress in the carrying zone should be around $1000 \mathrm{~Pa}$, which is the typical order of magnitude of the yield stress in robotic extrusion. However it is also too high to expect a good impregnation of the roving, and this confirms the interest of the OLP process (more fluid, hundreds of Pa) including adapted accelerator and adapted length $l$.

\subsection{Fibre diameter matters}

The approach proposed in this article is inspired by composite materials, and as such, a roving diameter of $0.1 \mathrm{~mm}$ is considered in the presented experiments. This is a significant difference compared to previous processes implemented in long-fibre extrusion, which used co-extrusion of mortar and rovings or rope with

255 a diameter in the millimetric or even centimetric range [5]. The fibre diameter can indeed be correlated to the quality of the bonding between the fibres and the matrix.

To illustrate this correlation, we consider $n$ fibres of diameter $\phi$ in a lace of length $L$ and diameter $D$ with a constant volumic fraction $\eta$. Such laces are shown in Figure 4. The pull-out force of fibres is closely related to its specific
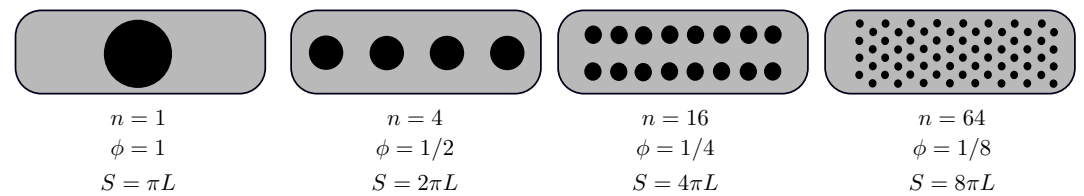

Figure 4: Cross-section of laces with the same fibre volume, but different fibre diameter $d$. The surface area of contact $S$ increases as the diameter decreases.

surface area, i.e. the surface area of contact $S$ between the fibres and the matrix, especially if the latter is homogeneous. First, we consider a constant volumic fraction $\eta$ of fibres in the lace: writing correspondence between volumes and simplifications leads to Equation (3).

$$
\eta D^{2}=n \phi^{2}
$$

The surface area of contact between the fibres and the matrix can thus be determined with Equation (4). The surface area is inversely proportional to the fibre diameter $\phi$.

$$
S=n \pi d L=\frac{\eta \pi D^{2} L}{\phi}
$$

Therefore, the difference between a typical rebar where $\phi \sim 1 \mathrm{~cm}$ and the approach proposed in this article, with $\phi \sim 0.1 \mathrm{~mm}$ is non negligible, as the surface area of contact is multiplied by 100 for the same volumic fraction $\eta$, which should 
improve significantly the bonding between fibres and matrix at a material scale. This simple scaling argument is a useful indicator to understand the influence of diameter, but it neglects the fact that bonding quality depends on the fibre scale, because of concrete heterogeneity. For example, the trend observed with concrete rebars in building codes [1] is that the bond quality decreases as the rebar diameter $\phi$ increases. Therefore, the argument is a first order approximation, as other factors may affect the bond quality between fibres and mortar.

275 Another look at this issue, which takes into account the heterogeneity of concrete based on many experiments is the design approach recommended in building codes such as ACI Building Code 2 or Eurocode 2 [1], which proposes a development length that is proportional to the rebar radius in usual conditions. With good bonding conditions, and proper cover $c_{d}>3 \phi$, the development length is typically superior to $20 \phi(1, \S 8.4 .4)$. If the designers want to comply to the philosophy of these standards, this means that a proper anchorage between reinforcement and mortar can be achieved only if the wall thickness is far superior to the reinforcement diameter. In our case, with fibres of $0.1 \mathrm{~mm}$ and a wall thickness in the centimetric range, this is clearly achieved. Some experi285 ments concerning the anchorage mechanisms between such small aligned fibers and the cementitious matrices used for 3D printing in this work, are presented in a previous publication of the authors [14. Tension tests on mono-filaments embedded in the matrix are achieved and in-situ X-ray tomographic observations of microcracking patterns are observed along the test.

\subsection{First experimentations}

In this part, a description of the firsts experiments and observations realised with the prototype device is proposed.

\subsubsection{Materials : Matrix and reinforcement properties}

The matrices are printable mortars designed for robotic extrusion, already at

use at the laboratory for full-scale experiments : One is provided by Lafarge (Lafarge 3DPG), the other (Navier material) has been designed at the laboratory (for reference composition see Table 1). Reinforcements are Isomatex Filava Conventional Multi-End 400 tex basalt rovings and NEG AR310S800 310 tex AR-glass rovings. For more detail see Table 2

\begin{tabular}{||cc||}
\hline Ingredient & Mass proportion \\
\hline \hline Cement & 0.28 \\
Water & 0.11 \\
Sand & 0.44 \\
Silica fume & 0.16 \\
Superplasticizer & 0.003 \\
\hline
\end{tabular}

Table 1: Reference composition of the Navier printing mortar. 


\begin{tabular}{l||ccccccc||}
\hline Name & Material (-) & Titer $($ tex $)$ & Density $\left(\mathrm{g} / \mathrm{cm}^{3}\right)$ & $A\left(\mathrm{~mm}^{2}\right)$ & $f_{f i l}(\mathrm{MPa})$ & $E_{f i l}(\mathrm{GPa})$ & $\varepsilon_{\max }(\%)$ \\
\hline \hline NEG AR310S800 & AR glass & 310 & 2.80 & 0.110 & 1500 & 74 & 2.0 \\
Isomatex Filava & Basalt & 400 & 2.61 & 0.154 & $3400-3700$ & $88-94$ & 2.4 \\
\hline A: Cross-section area of the filament; $f_{f i l}:$ tensile strength of the filament; $E_{f i l}:$ Tensile modulus of the filament; $\varepsilon_{\max }:$ ultimate strain.
\end{tabular}

Table 2: Characteristics of the fibre reinforcement used for FBP.

\subsubsection{Flow-Based Pultrusion apparatus : Roving conveying, fibre} impregnation and pulling

A view of the printing process is presented in the Figure 5.10 bobbins each
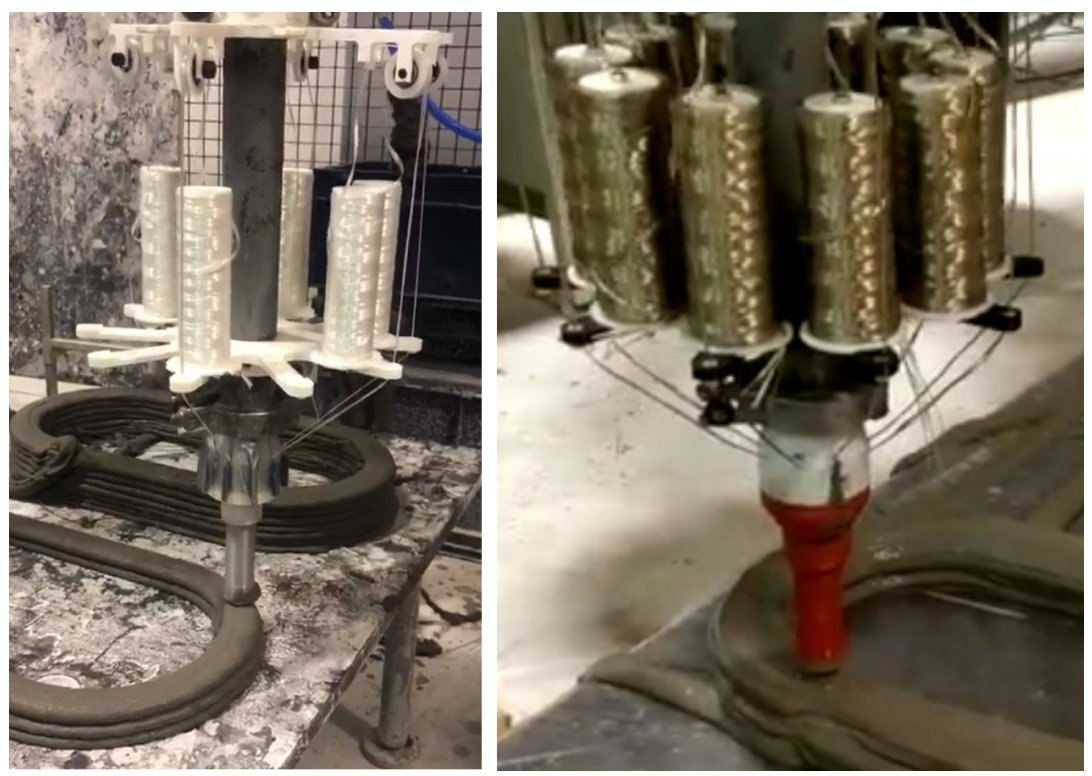

Figure 5: 3d printing of anisotropic concrete.

provide 30 meters of roving for a fiber ratio of about $0.8 \%$. Increase this ratio is possible easily using more industrial developments and different layers of bobbins. Another previous attempt with more fibers can be seen in Figure 6 where heavier rovings were used.

As small roving packages are impossible to find due to the lack of industrial applications, these small bobbins are wound from standard bobbins using a custom apparatus permitting a very controlled roll-up, avoiding knots, and 310 minimizing friction. On the right of Figure 5 a zoom is made on the printing nozzle, where additives are added and mixed, rovings are impregnated and pulled by the mortar. Schematic view is proposed in Figure 7. Rovings are conveyed through PTFE pinholes $(1,3)$, pulleys $(2)$, and inserted in the matrix through a PTFE tube (4). Knowing that the additive effect is time dependant, 315 the yield stress of the concrete matrix increases with time, the output pipe has to be long enough to ensure that the concrete flow becomes sufficiently firm to 


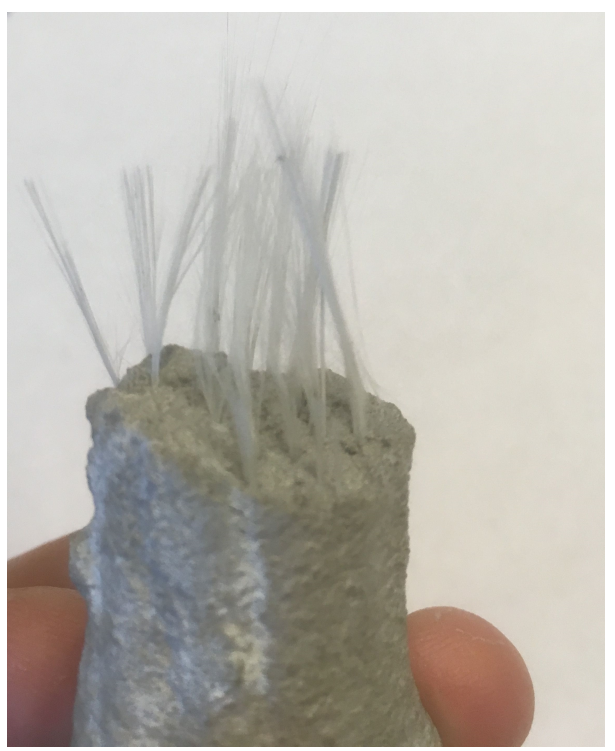

Figure 6: Lace with $1 \%$ fiber by volume.

pull the fiber. More rheological and specifications may be found in [10]. Finally, the resulting anisotropic concrete is extruded out of the nozzle end.

The robotic path is designed here to print quasi square boxes, with different 320 lace thickness. The result of those fibred printing are shown in Figure 5 . The global good aspect is the proof that the system works rather well. In particular, due to the curve shape of the path, any unexpected relative displacement between reinforcement and matrix in the extruded lace should lead to the extraction of the roving, pulled by the nozzle advance. To better understand this risk/phenomenon, just imagine that a bobbin suddenly stops spinning, due to excessive frictions and insufficient flow shear forces. The consequence will be a tension in the roving already deposited, and its immediate extraction of the lace. Only once, such a bobbin blocking occurred during our printing. The answer is the immediate cutting of the concerned roving. Another key point is 330 that only the shear stress control permits here to negotiate curves correctly, as during a curved path, the inside bend rovings must have a smaller deposition speed than the outside bend rovings. The modification of the concrete flows inside the nozzle as said before, plays the role of a differential gear.

These first results, obtained with this first laboratory prototype, confirm the 335 rheological analysis and the Flow-Based Pultrusion strategy. The potentialities seem important, and in the next parts we try to explore some of them, both concerning the unexpected facilitation of the $3 \mathrm{~d}$ printing process itself, and the innovative structural applications it offers. A first part concerns thus the study of the properties of anisotropic concrete at fresh state, a second one the mechanical properties at hardened state. 


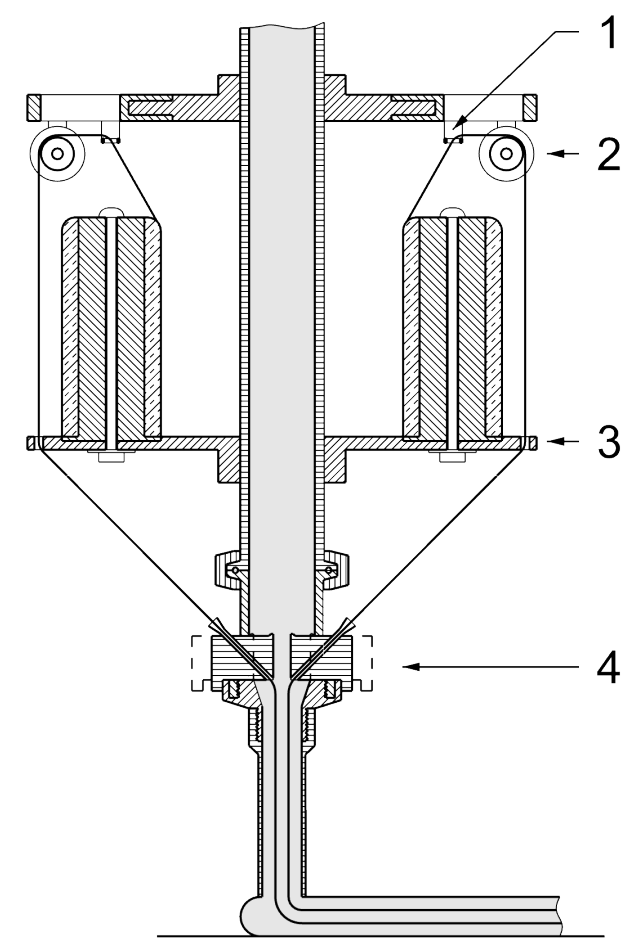

Figure 7: Section of the experimental device.

\section{Properties of anisotropic concrete at fresh state}

\subsection{Considerations and observations}

As mentioned earlier, a key point concerning the robotic extrusion of concrete, is the mastering of the material behavior, yield stress, thixotropy, and its evolution through time. Even for standard horizontal lace deposition patterns, many parameters must be controlled to avoid collapses during deposition, to permit a good bonding between layers (avoid cold joints), to ensure an accurate geometry. For a more complex robotic path, including slopes and cantilever situations the problem will become really tricky and these parameters have no choice but to be real-time adjusted. And to do that, the Oriented Lace Pressing (OLP) is definitely a good alternative to the Extrusion Lace Shaping (ELS) one. More versatile since real-time adjustable, OLP is however also very sensitive due to the weak yield stress of a more fluid extruded material. Illustrations of these difficulties are shown in Figure 8. One can see local and more catastrophic buckling due to a lack of structuration. The material is not able to carry the weight load of the laces above. The reason is a too weak yield stress, locally and at a given time $t$. 

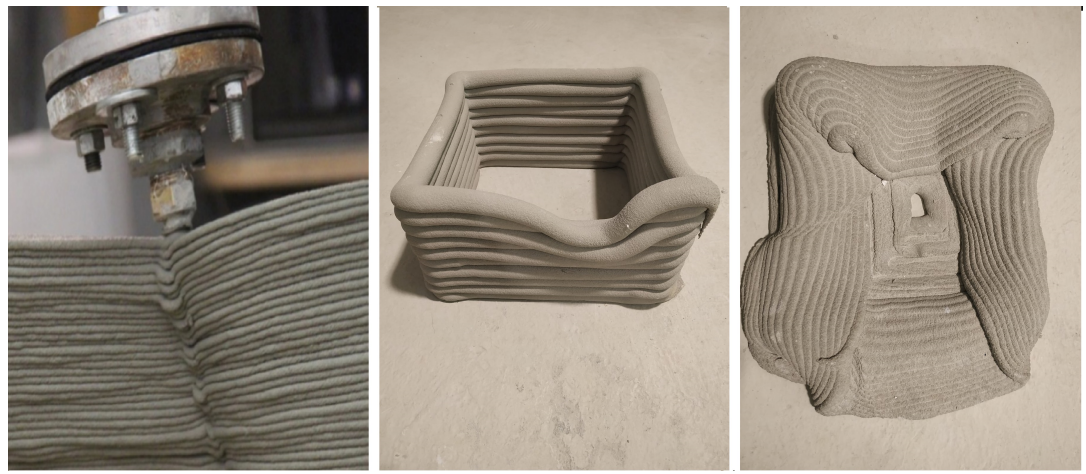

Figure 8: Local and global defects due to a lack of consistency during OLP printing (the left view from [18, right view from [6])

The tuning of the right consistency of the paste from soft to firm permitting the impregnation, the pull out of the fibers, and the buildability, depends on, additives, shear stress level (prescribed by the endless screw), speed of the robotic path, pressures and flow, length of the final pipe of the nozzle, and the all-set is very difficult to mastered. But it is well-known that mixing short fibers in a paste changes its rheological properties. What about using long fibers? May 365 have a look to the Figure 9. On the left is an illustration of a classical OLP printing operation, the consistency is quite perfectly adapted to standard printing. One can see the drop formation and its characteristic length, from which the actual yield stress can be identified (see from the same authors, the slug test description 16]). On the right Figure is a printing of the same material but with only $0.2 \%$ ( 5 light rovings) of continuous fibers.

The difference is striking : the consistency of the lace permits easy handling and avoids slug effect even though the matrix remains the same. Cold joints are not a problem since the external surface of the lace remains very fluid even though the global firmness is very high. On the right Figure 9, a scissor-cut is realised. The result is a very clean slice, impossible to achieve on the fiber-less mortar. An interesting perspective for industrial production, to achieve slopes and cantilever situations.

\subsection{Some first measurements}

In order to evaluate the effect of fibres on the fresh behaviour of the printed material, a simple experiment is proposed (see Figure 11). The FBP process is run statically, so to continuously extrude laces that are only subjected to the gravity and to the mechanical effects due to fibres interactions. At some point, the extruded lace will drop. When three lace's drop have been observed, the

number of rovings is decreased by cutting one. The initial roving count is set

to 10 . The experiment is video-captured to analyze the shape, the maximal 

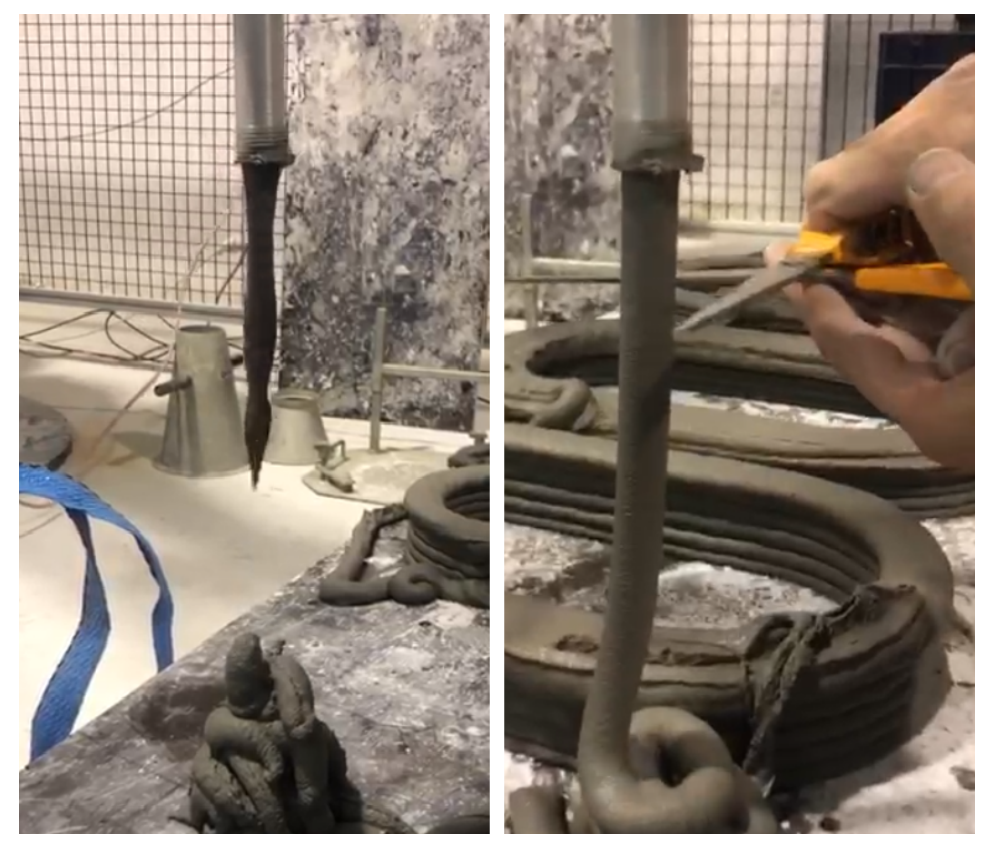

Figure 9: Lace behavior without (left) and with $0,2 \%$ fiber by volume (right) same cementitious formulation.

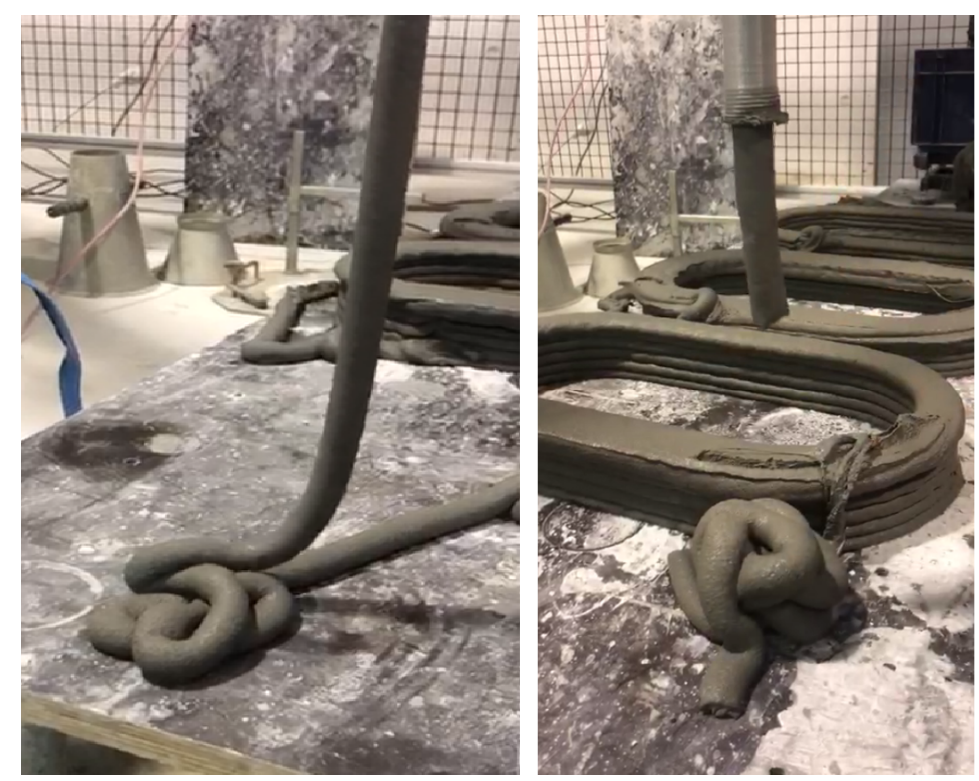

Figure 10: easy-handling of a lace with $0.2 \%$ fiber by volume, and sharp result of a cissor cut. 
length and the extrusion time of laces until ruin. A slug test [16] run before the experiment allowed to set the output yield stress of the mortar to $550 \mathrm{pa}$, which is rather low. This allows a better sensitivity to effects that are specific to the fibre reinforcement, by minimizing the plain mortar consistency.
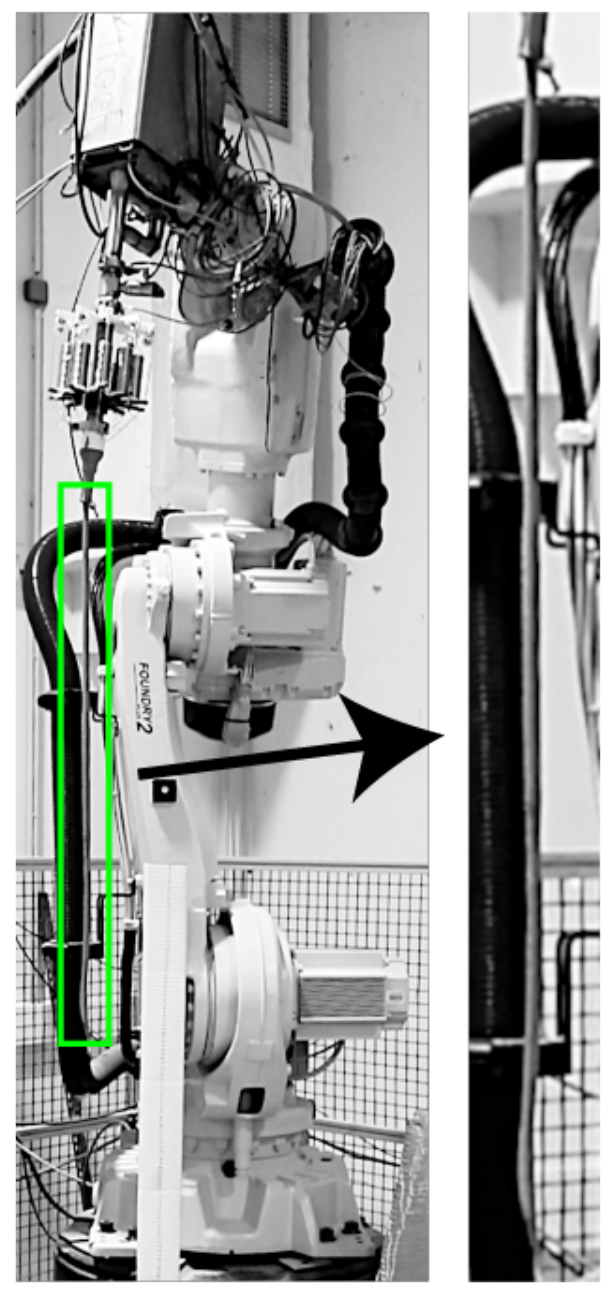

Figure 11: Photo of the experiment and zoomed view of the reinforced lace.

\section{Properties of anisotropic concrete at hardened state}

In this section, a methodology and first experiments are proposed to evaluate the mechanical performance of anisotropic concrete. The volume ratio of the 


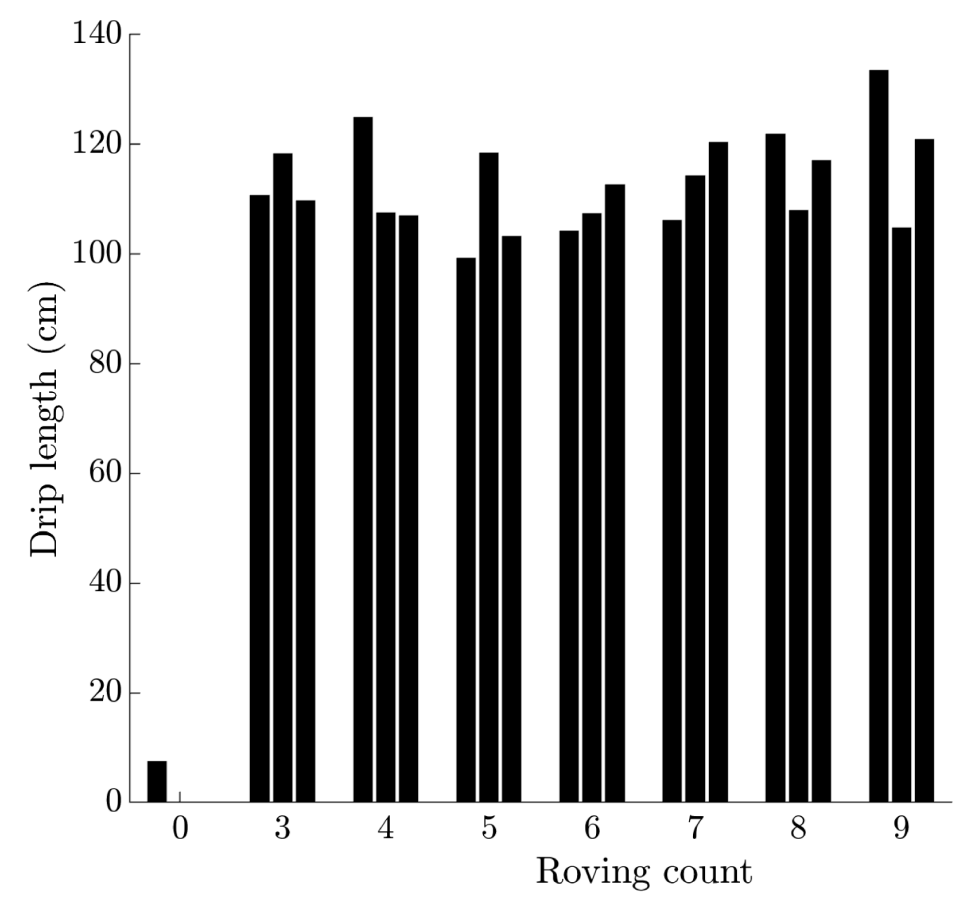

Figure 12: Drip lengths against roving count. 
fibers and the kind of the matrix (low or high strength) are some very important parameters and we have to comply with the possibilities of the device presented in Section 2.4. The number of bobbins can be up to 10, and rather high strength matrices have to be used for $3 \mathrm{D}$ printing specifications. These limitations may be overcome through future technological developments. Indeed, examples of 400 robotized manufacturing processes using many more rovings may be found. One could cite the automated braiding of carbon preforms [28] where 36 spools are tested on a device allowing up to 144. Concerning matrix strength, if mechanical performances of the matrices could be tailored by modifying the water to cement ratio and the cement quantity, printability is constrained by rheology 405 and a need of high cement rate 35 to obtain an appropriate structuration rate. Consequently, 3d print with low rate of cement remains an open economical and environnemental challenge. But to explore in advance a wider field, higher fiber ratios and various matrices, a bench-top extruder called here Extrusion Moulding (EM) has been developed to extend the scale:1 printing device. This set of devices allows to understand better the material behavior and to identify ways to improve the printed material properties. The EM device consists of extruding a printable mortar in a mold where rovings are already placed, as shown in Figure 13. Although fibres are not pulled by flow as in Flow-Based Pultrusion (FBP), this method provides a comparable hardened material even ${ }_{415}$ if more controlled and more defectless (see Section 4.3.1). As more versatile and less time and material consuming, EM is very convenient for a parametric study and to catch the main phenomena and tendencies. EM allows to place up to 40 rovings in a custom printable matrix.

By varying the fibre count and matrix strength, different behavior have been experimentally obtained for FBP and EM reinforced specimens, as pseudo strain hardening or multicracking. This is especially interesting as may improve the ductility and mechanical properties. These phenomena are well-known for brittle matrix composites 22] and even for fibre reinforced concrete [40]. The conditions for a multicracking are influenced by matrix, fibre-ratio, interface prop${ }_{425}$ erties, and by cracking energy. In [22] a theoretical analysis is made showing that this last point is crucial, and that the fibre ratio and a rule of mixture are not sufficient to predict the pseuso strain-hardening and multicracking. The toughness of the matrix, the critical strain energy release rate, the interface qualities, the fiber diameter are also very important. The required volume fraction 430 to obtained pseudo strain-hardening increases for a matrix of higher fracture toughness. For ceramic composites it is more difficult to achieve when compared to cementitious matrices. As our cementitious inks are high performance concrete, EM specimens permit to explore in advance formulations with lower performance matrices, and higher fiber ratio.

435 In a first part, we describe the EM and FBP specimens for tension and 4-point bending tests. For FBP, single-layer and multilayers specimens are produced. Then tension tests and bending tests are described and commented. 


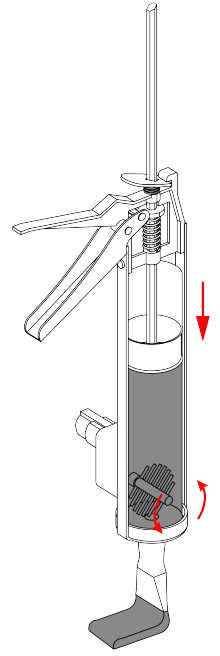

(a)

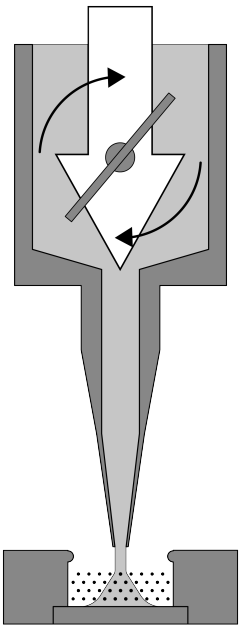

(b)

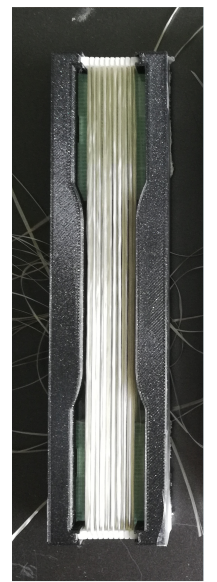

(c)

Figure 13: Bench-top Extrusion Moulding (EM) device (a) the mixing system, (b) Matrix injection in sample mold.(c) Photo of the sample mold with fibres before injection.

\subsection{Preparation of specimens}

\subsubsection{Preparation of EM single-layer specimens for tension and bend- ing}

Specimens are realised with the device presented above and showed in Figure 13 Figure 14 shows a schematic of the test specimens geometry. The cross-section is set to $18^{*} 8 \mathrm{~mm}^{2}$, similar to a printed lace.

Different fiber-ratio are used, from $0.8 \%$ to $6 \%$. Fiber-ratio is controlled by varying the fibre count (Figure 15) and fibre material (see Table 2). Unreinforced specimens were also produced, with short metallic fibres added in the grip zones. Matrices are listed in Table 3

Preparation of the mortar The mortar preparation procedure is adapted from robotic extrusion experiments, following those steps : solid ingredients are mixed in a 5L table mixer at slow speed while liquid ingredients are poured in a steady stream. The mixing bowl is then scraped before fast mixing for an additional 6 minutes to reach a smooth mixture. Given that the purpose of the experiment is to reproduce conditions similar to FBP, control of matrix yield stress is of great importance. The target yield stress value of the mortar is set as 455 the "entry" (before adjuventation) yield stress of FBP, namely between 50 and $100 \mathrm{~Pa}$ [15. It is checked by carrying a slump test, using an ASTM minicone. This type of test is widespread in concrete industry and results can be used for 


\section{$\underline{\text { Direct tension }}$}

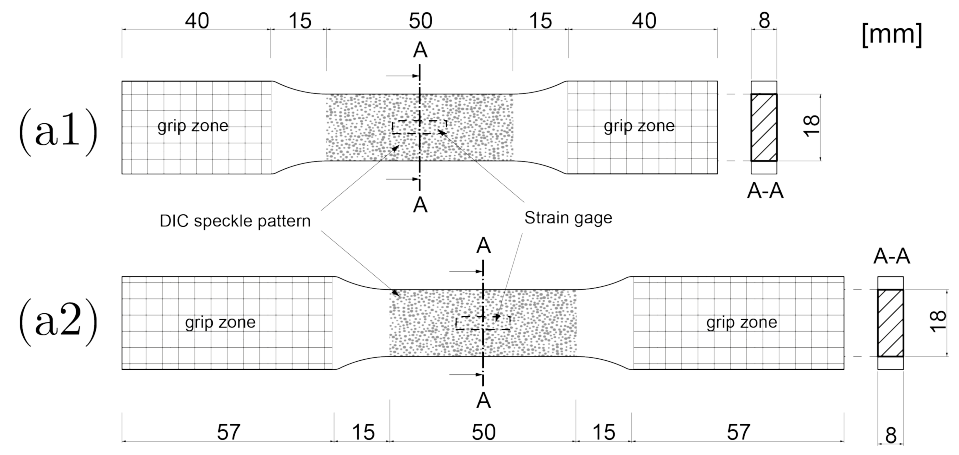

\section{$\underline{\text { Bending }}$}

(b)

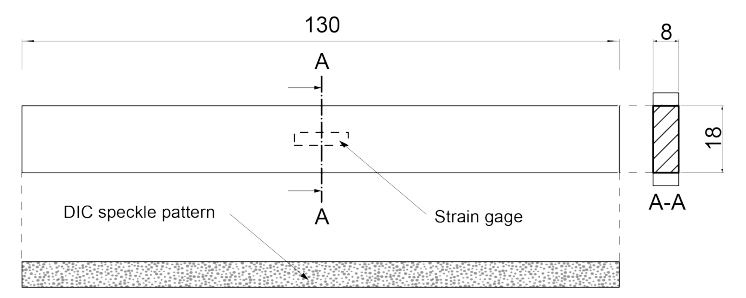

Figure 14: Schema of EM specimens geometry.

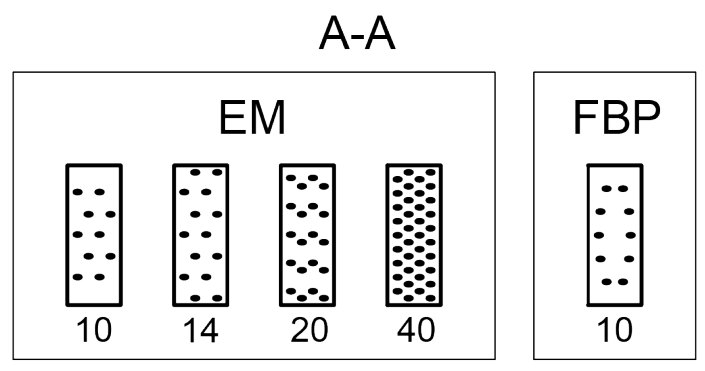

Figure 15: Detail of fibre layouts for EM and FBP single-lace specimens. 


\begin{tabular}{|l|l|l|}
\hline Matrix & Mechanical properties & Processes \\
\hline 3DPG (28-day curing) & High & EM,FBP \\
\hline Young-age 3DPG (7-day curing) & Low & EM \\
\hline
\end{tabular}

Table 3: Listing of matrices and processes.

\begin{tabular}{|l|l|l|l|l|l|}
\hline Set & Roving designation & Roving titer (Tex) & Roving count & Vf (Fibre-ratio) & Average impregnation yield stress $\left\langle\tau_{c}\right\rangle$ \\
\hline 1 & Isomatex Filava & 400 & 10 & $1 \%$ & $302 \mathrm{~Pa}$ \\
\hline 2 & NEG AR310S800 & 310 & 10 & $0.8 \%$ & $325 \mathrm{~Pa}$ \\
\hline
\end{tabular}

Table 4: Table of reinforcement parameters of FBP single layer specimens.

yield stress estimation [34]. for the purposes of simplicity, no adjuventation is used for EM.

Mortar mixing and extrusion The printable mortars used in this study are thixotropic : their fresh properties are impacted by the material stress history. So as to make the EM process similar with FBP, it is then important to follow a similar material history. In the case of FBP, mortar is sheared by mixing just before extrusion and this particular aspect is reproduced for EM by using 465 the mixing syringe shown in Figure 13 a. Such as for any concrete mixer, it also avoids segregation and maintains homogeneous properties from specimen to specimen. Finally, specimens are cured in a humid environment for 1 day, immersed in water for 27 days and unmolded. For one specific batch, curing time was reduced to 7 days to lower matrix strength.

\subsubsection{Preparation of FBP single-layer specimens for tension and bending}

In order to provide FBP specimens as close as possible than EM specimens, and as thin as possible, straight laces were printed in order to die-cut single-layer specimens. Geometry is the same as EM samples (Figure 14). They are cut while the material is fresh just after printing, as shown in Figure 16. The surface is gently tapped to provide a regular aspect. Then, specimens are cured in a humid environment for 1 day, immersed in water for 27 days and unmolded. Matrix is a Lafarge 3DPG mortar (see Table 3). Reinforcement fibre rovings are Isomatex Filava 400 Tex and NEG AR310S800, amongst the other FBP${ }_{480}$ compatible types listed in Table 2.

\subsubsection{Preparation of FBP multi-layer specimens for bending}

Right after the printing process described in Section 2.4 as for other specimens, the printed square boxes are cured in humid environment for 1 day and

485 immersed in water for 27 days. Multilayer beam specimens are sawn out of the printed walls, with constant length $(200 \mathrm{~mm})$ and varying sections, average $30 x 30 \mathrm{~mm}$. Matrix is a Lafarge 3DPG mortar (see Table 3), reinforcement 


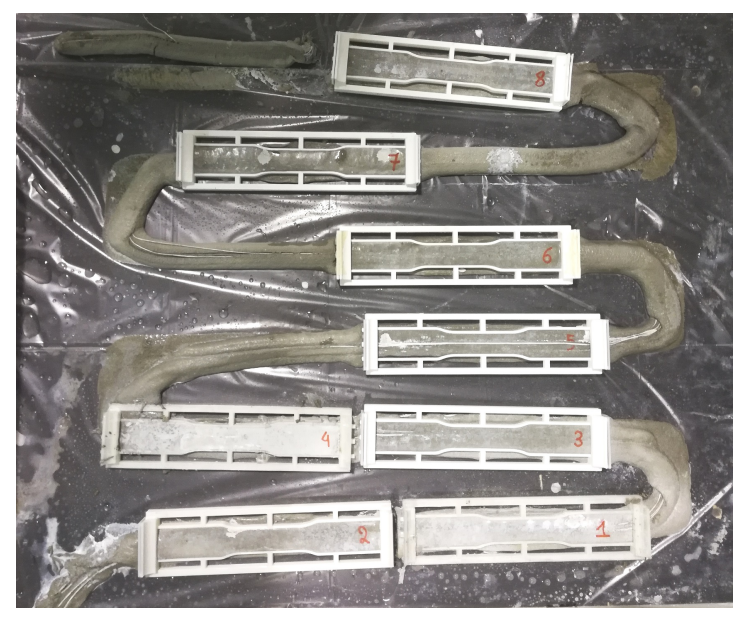

Figure 16: Die-cut FBP single-lace specimens.

is NEG AR310S800 (10 rovings/layer). Different layer heights and thicknesses were set to provide global reinforcement ratios of the lace going from 0.5 to $0.7 \%$ . Due to the edge drainage of free matrix, locally (near the center of the lace) the reinforcement ratio is higher, up to $1 \%$. Unlike to the EM or single-lace FBP specimens, here the specimen size is not prescribed by a mold and is dependent on the printing process settings (Figure 17). As the geometry of the sections of the specimens present some variations, each section is photographed and a ${ }_{495} \mathrm{CAD}$ software compute cross-section parameters such as the neutral axis and the area moments, as shown in Figure 18. In these calculations the mechanical influence of the fibers are neglected. Unreinforced reference samples were also produced.

\subsubsection{Preparation of notched FBP multi-layer specimens for bending}

As said before, not only the fiber ratio, but also the toughness of the matrix, and the critical strain energy release rate after a crack initiates, are also very important. As existing cementitious inks are tough concrete, we proposed EM specimens permitting more weak matrices, but another way to decrease the available elastic energy when cracking is to use notched specimens. They should permit a less brutal propagation, and consequently a larger pseudo strain-hardening behavior. Thus, two notched multilayer specimens were prepared, with $100 \mathrm{~mm}$ and $200 \mathrm{~mm}$ span (Figure 19). The notch depth is $3 \mathrm{~mm}$. The notch is obtained with a diamond wire saw providing a $1 \mathrm{~mm}$ cut width. Matrix and reinforcement are the same as unnotched multilayer specimens. 


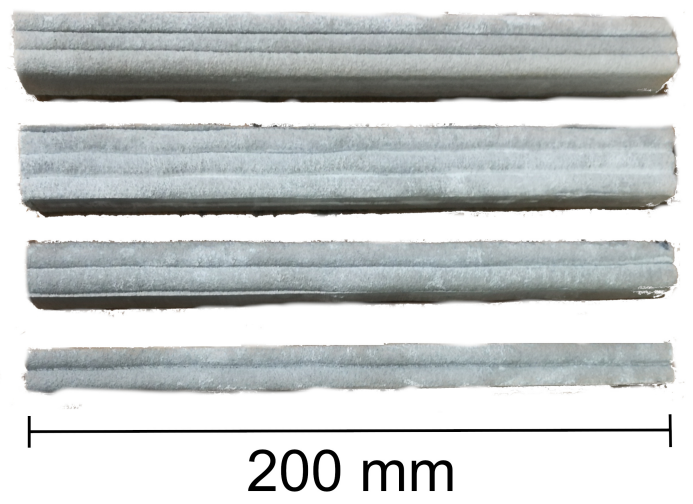

Figure 17: FBP Multi-layer beam specimens.

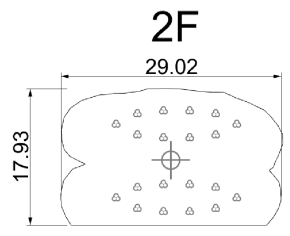

Ix : $11583.93 \mathrm{~mm} 4$

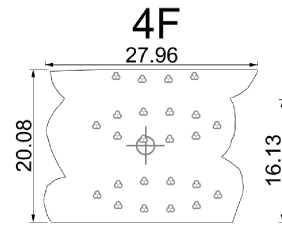

Ix : $16909.07 \mathrm{~mm} 4$

[mm] $\phi$ Centroid

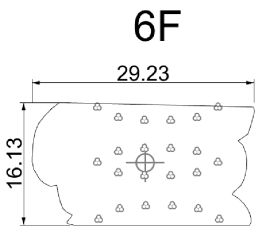

Ix : $8481.69 \mathrm{~mm} 4$

$\vec{x}$

Figure 18: Drawing of $2 \mathrm{~F}, 4 \mathrm{~F}$ and $6 \mathrm{~F}$ specimen sections. Ix denotes the second area moment with respect to the $\mathrm{x}$-axis.

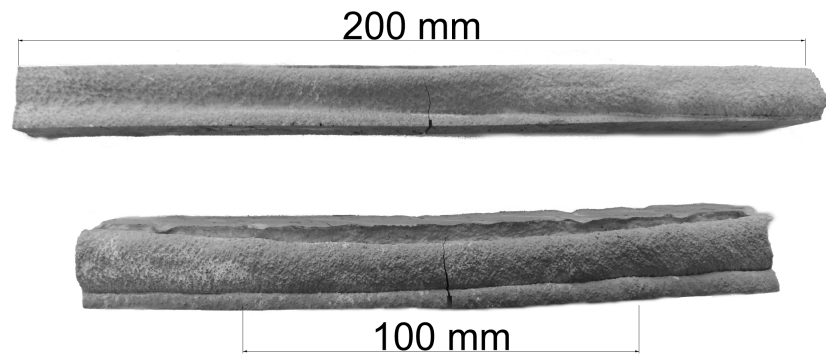

Figure 19: Notched FBP multi-layer beam specimens after testing. 


\subsection{Test methods}

\subsubsection{Direct tension tests of single-layer EM and FBP specimens}

Figure 20 shows a typical specimen during testing. Tests were performed in displacement control (rate $=0.005 \mathrm{~mm} / \mathrm{s}$ ) using a Instron universal testing machine. Both ends of the specimen were held by machine grips. In order to perform Digital Image Correlation (DIC) measurement of strain, a speckle pattern was applied to one side of the specimen using spray paint. Measurements were performed with a Allied Vision Prosilica GX3300 camera and a custom MATLAB code. Specimens were also instrumented with a Kyowa KFGS-5-120C1-11 strain gage centered in the longitudinal axis on the unpainted side. A MF MFA 2 clip-on extensometer was eventually used to complete the measurements.

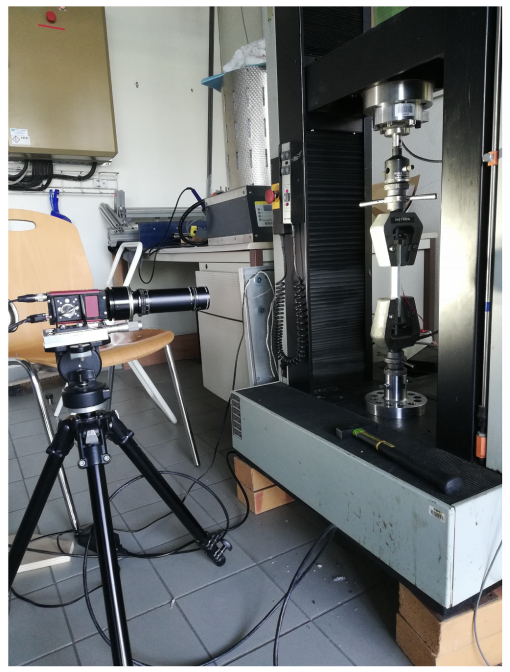

(a)

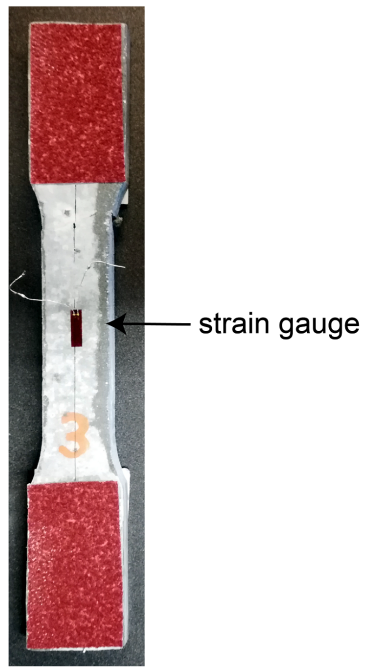

(b)

Figure 20: (a) Tensile test setup with photogrammetric measurement. (b) the back side of test specimen and strain gauge.

\subsubsection{4-point bending test of EM and FBP single-layer specimens}

Four-point bending tests were performed at 28 days using an Adamel universal testing machine with a $1 \mathrm{kN}$ load cell (Figure 21). The displacement rate was ${ }_{525} 0.005 \mathrm{~mm} / \mathrm{s}$. Strain measurements are carried by DIC and a strain gauge, with the same method as direct tension test (see Section 4.2.1). 3 reinforced, 1 unreinforced EM specimens and 1 reinforced FBP specimen were tested. 


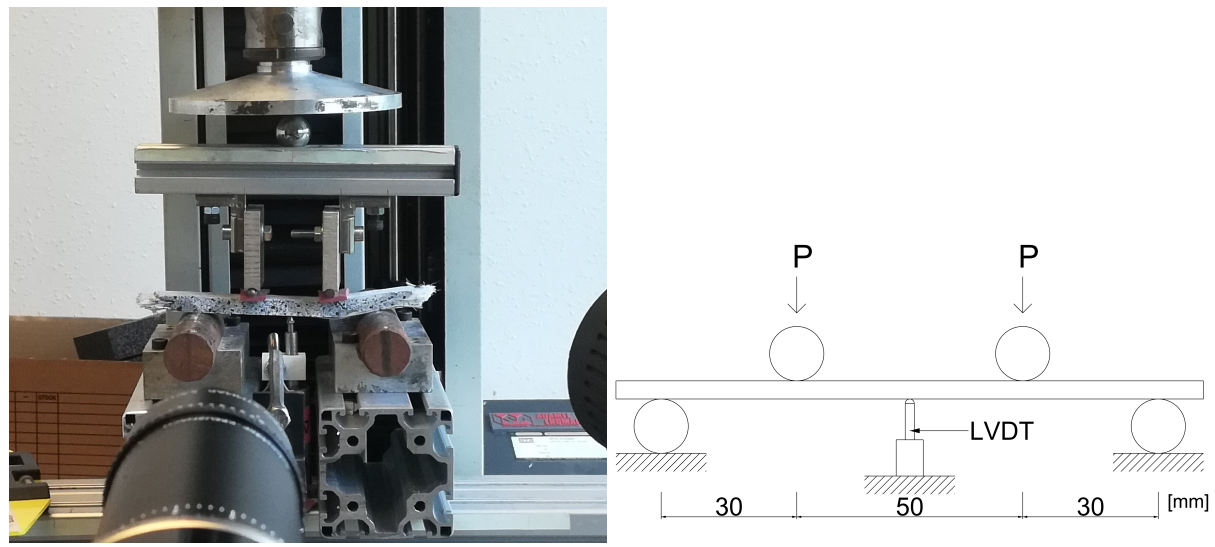

Figure 21: View and schema of the test setup for 4-point bending of single-layer specimens.

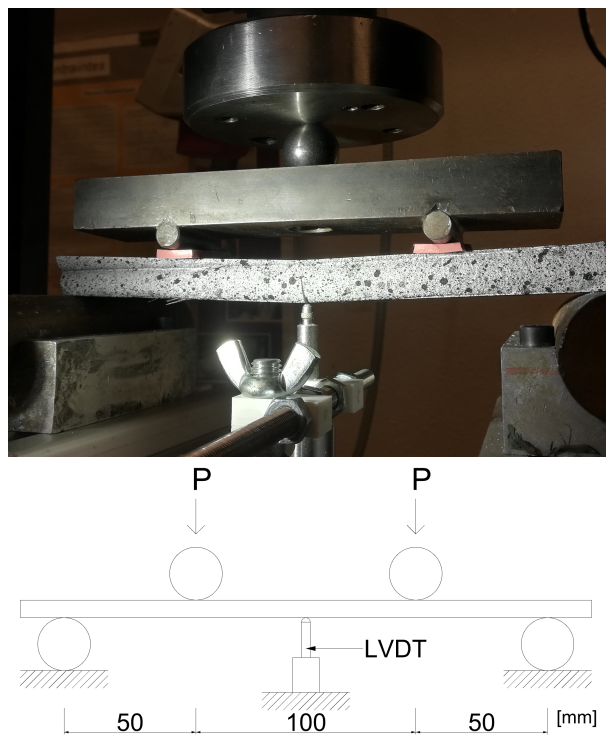

Figure 22: View and schema of the test setup for 4-point bending of multi-layer specimens. 


\subsubsection{4-point bending test of unnotched and notched FBP multi- layer specimens}

530 Four-point bending tests were performed at 28 days using an Instron universal testing machine with a $10 \mathrm{kN}$ load cell (Figure 22. The displacement rate was $0.05 \mathrm{~mm} / \mathrm{s}$. Strain measurements are carried by DIC and a strain gauge following the same setup as in the direct tension experiments (see 4.2.1). For unnotched specimens, 5 reinforced and 2 reference specimens were tested. For notched specimens, 2 reinforced specimens were tested.

\subsection{Test results}

Firstly a brief comparison between EM and FBP tension specimens with close characteristics (kind of fibers, fiber-ratio...) validates the fact that the 2 processes are comparable. Then different tension and bending tests on EM, FBP and notched FBP specimens are presented and some conclusions highlighted.

\subsubsection{Direct tension of similar EM and FBP specimens}

EM and FBP tension specimens, either reinforced using 310 Tex Glass rovings or 400 tex basalt, are compared by direct tension tests. Firstly the fracture profiles 545 are very similar for the both processes, (Figure 23) showing same roughness and mixed brooming and fibre rupture.
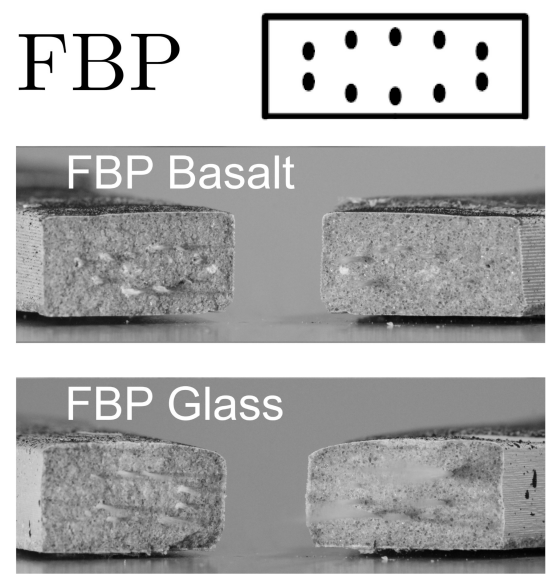
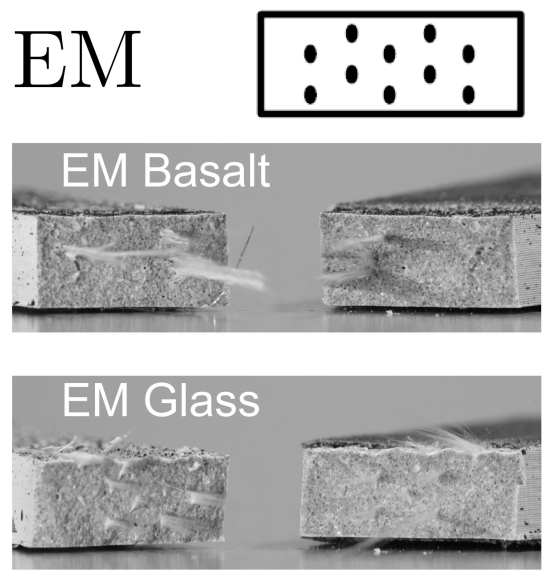

Figure 23: Tilted view of FBP and EM specimens rupture profiles.

Figure 24 shows different stress-strain curves for these EM and FBP specimens. Their appearance are very close and the order of magnitude of stiffnesses, strengths and pseudo strain hardening are comparable even if the tabletop specimens have slightly higher resistances. Note also that due to the brittle behavior 
of the tough matrix, these direct tension tests are very sensitive to defects and test imperfections, and for both processes some specimens have brittle-elastic behavior with sometimes (Figure 24) a higher stength. To conclude, both processes can be considered comparable even if EM seems to provide less defect in the material, appearing as a kind of higher-bound of what is achievable with FBP. Some factors may explain this situation :

- For EM, smaller matrix quantities, smaller extrusion nozzle, permit certainly a more defect-free cement than for FBP. Moreover, to permit the penetration of the mortar around the rovings, specimens are vibrated which is not the case for FBP ones. This may improve the impregnation. Finally, the increase of yield stress is slower as no addition of additives during extrusion. This may improve also the impregnation.

- For FBP, industrial process, mixing, large pipes etc... may introduce more heterogeneity and defects in the matrix. Moreover fibres rovings may be damaged by their reconditioning into small bobbins, reducing strength.

\subsubsection{4-point bending of FBP specimens}

A representative stress-strain curve of the multilayer specimens behaviour with and without reinforcement is shown in Figure 25. Both exhibit a similar linear behaviour until reaching a flexural stress of $20 \mathrm{MPa}$. Then, unreinforced specimens fail catastrophically after the first crack. Reinforced specimens shows a stress drop (approx. 1/4 of the total load) after the first crack initiation, followed by a bell-shaped phase where the material reloads slightly while the crack propagates, before a smooth descent of stress accompanied with the crack opening. Then the pullout of residual reinforcement provides a smooth softening phase while the crack opens until complete failure.

The single-layer specimens show a very similar behaviour, and a representative curve is shown in Figure 26 .

These results highlight the potential of anisotropic concrete to provide ductility at single-layer and multi-layer scale, even at low reinforcement rates $(0.7 \%)$, and even with tough matrix, which is promising. However, due to this very brittle behavior of the matrix, some reinforced specimens also failed more brutally with more limited ductility, as shown in Figure 27.

The tests on notched specimens confirm the fact that for tough matrices the crack energy is determinant. Following the same method, multi-layer notched specimens of $100 \mathrm{~mm}$ and $200 \mathrm{~mm}$ length were tested and provided a good ductility (and a reduced resistance), as shown in Figure 28.

Indeed, failure of tough and brittle materials such as the high performance mortar used for FBP printed specimens is highly sensitive to the defects. Here, 590 the notch (as a pre-existing major defect) allows an earlier crack initiation with less available elastic energy. Such test relates to many situations where the material is already cracked (e.g. fatigue cracks, geometrical defects) and highlights the utility and efficiency of the proposed reinforcement, even for low fiber ratio. 

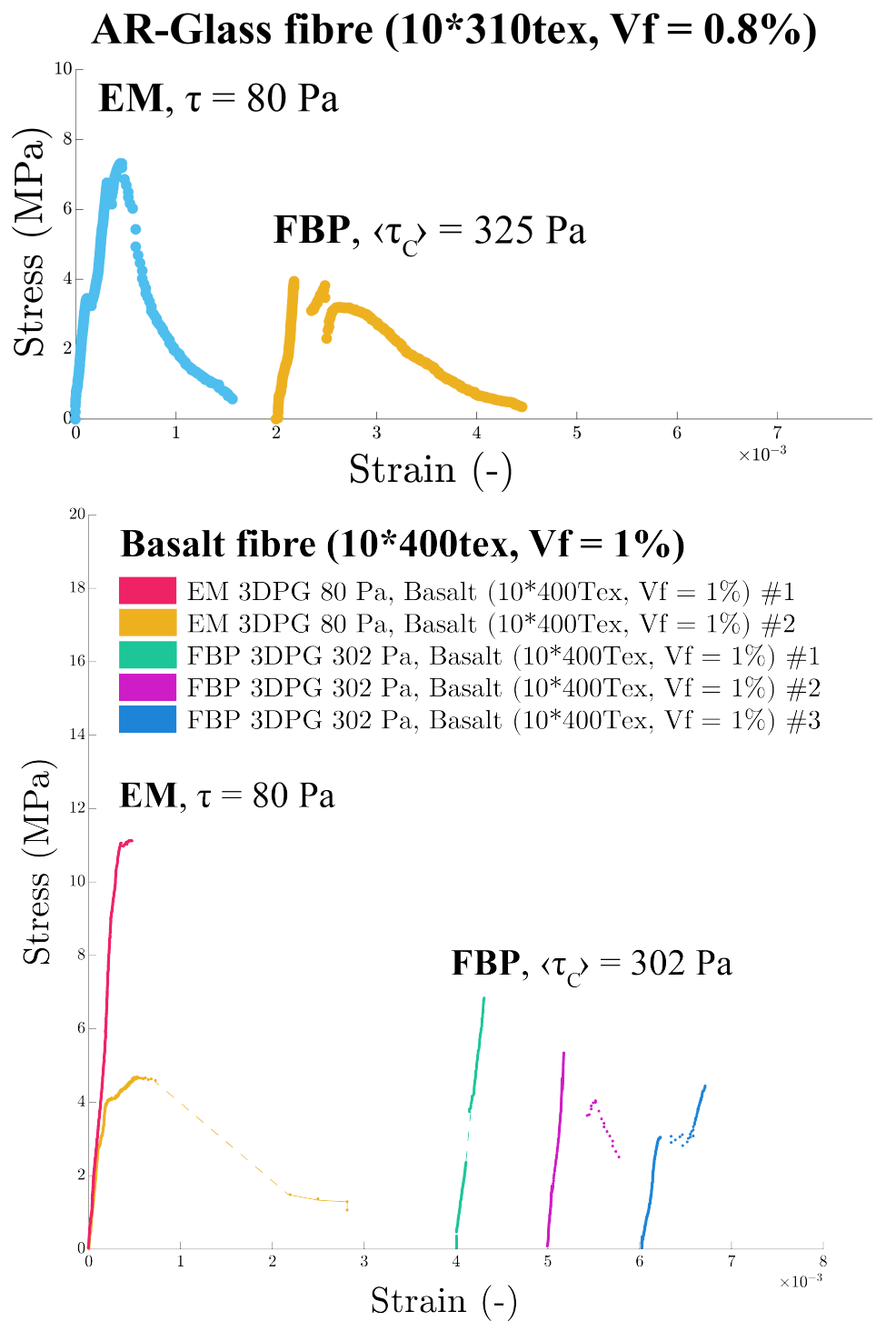

Figure 24: Stress-strain curves of EM and FBP direct tension specimens, reinforced with glass or basalt fibre. 


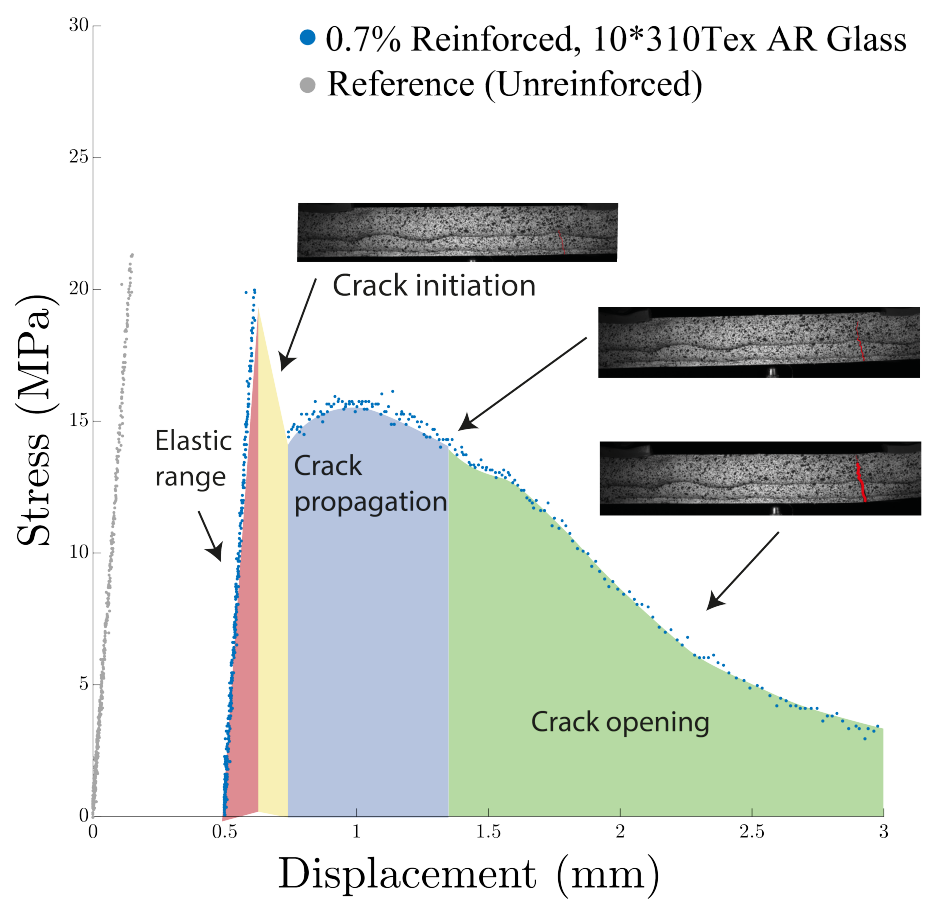

Figure 25: Representative stress-displacement curve for 4-point bending of 200x20x20mm multi-layer printed specimens.

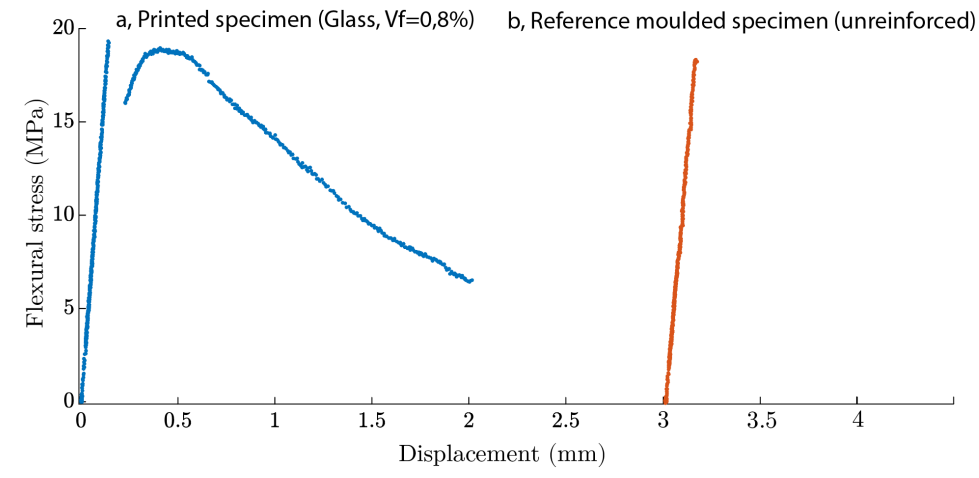

Figure 26: Representative stress-displacement curve for 4-point bending of 170x16x8mm single-layer printed specimens. 


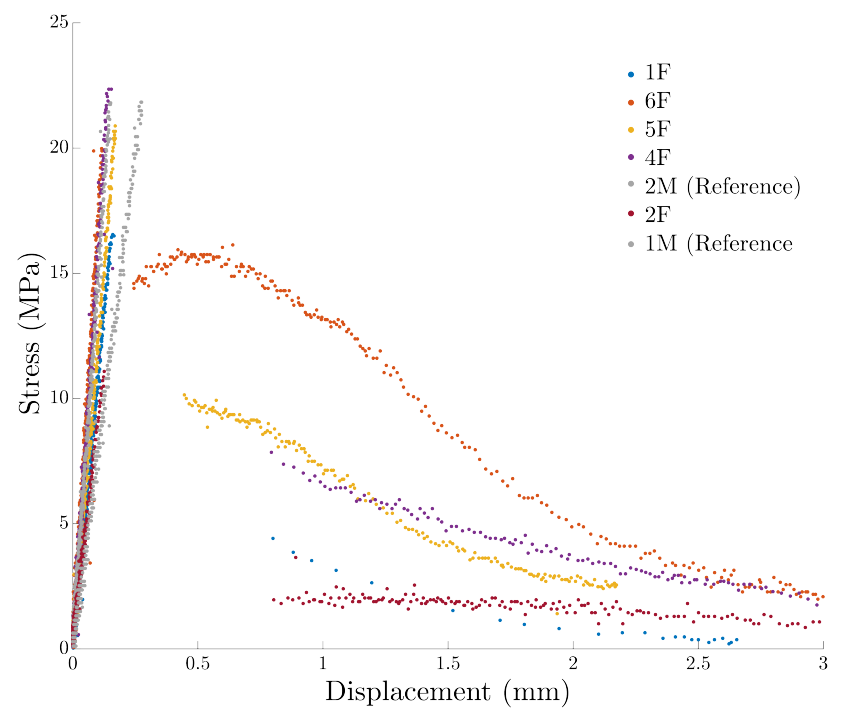

Figure 27: Stress-displacement curves for 4-point bending of 200x20x20mm multi-layer printed specimens.

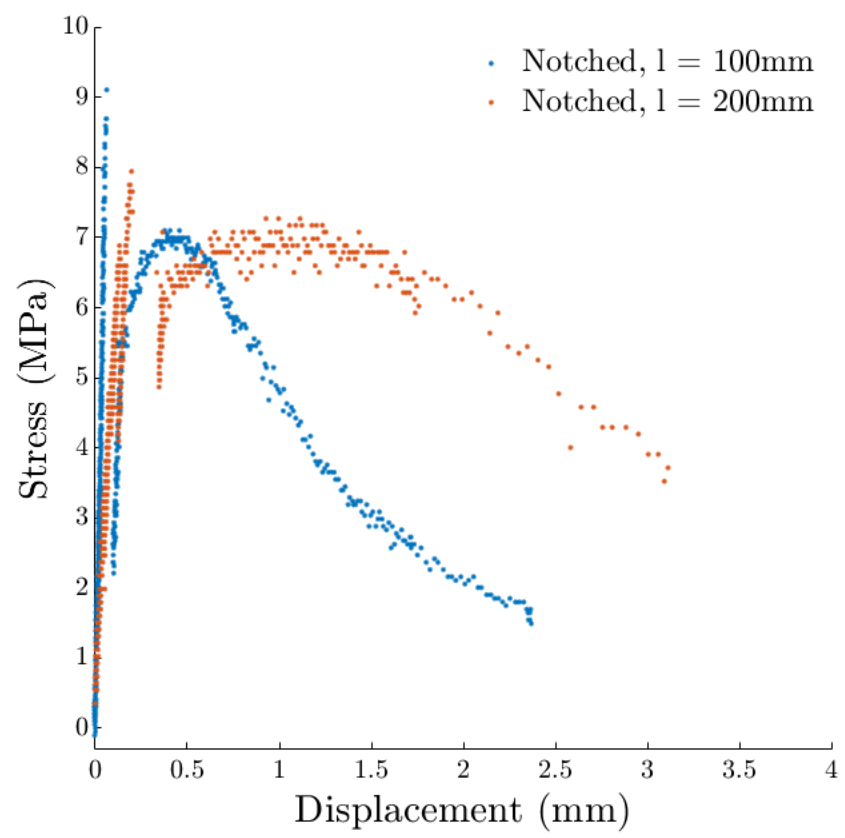

Figure 28: FBP multi-layer notched specimens. 


\subsubsection{Prospective results with EM specimens}

595 Here we summarize some additional and prospective experiments carried on the extrusion-moulded (EM) specimens. These tests permit, after be comforted that the 2 processes are comparable, to get out the limits prescribed by the present FBP device. They allow to explore the potential of the FBP concept to improve ductility and/or strength of anisotropic concrete. In particular, EM permits to 600 study the effect of different initial yield stress, of a less tough cementitious matrix, and the effect of higher fiber ratios.

Effect of the yield stress: a specificity of the OLP technology on which FBP is based on is the addition of yield-stress modifying adjuvents just before extrusion. By changing the additive dosing, one can control the yield stress of mortar at impregnation. Previous works by the authors on pull-out of mono-filaments shown the importance of yield stress on the bond properties 14 between fibre and mortar. This yield stress control may be mastered here by changing the matrix superplasticizer dosing in the EM process. Figure 29 shows the different stress-strain curves obtained for the same 3DPG matrix but with 2 different yield stresses, $75 \mathrm{~Pa}$ and $250 \mathrm{~Pa}$.

Here, very fine reinforcement (66 tex rovings) are chosen to ease the impregnation. Low yield stress specimens show fragile failure, without any pseudo strain-hardening (Figure 30 . This is due to the strong fibre/matrix bond, where fibres are directly broke when a crack propagates. High yield stress specimens ${ }_{615}$ allow some ductility, thanks to a weaker interface between fiber and matrix, allowing fibre pullout after crack opening.

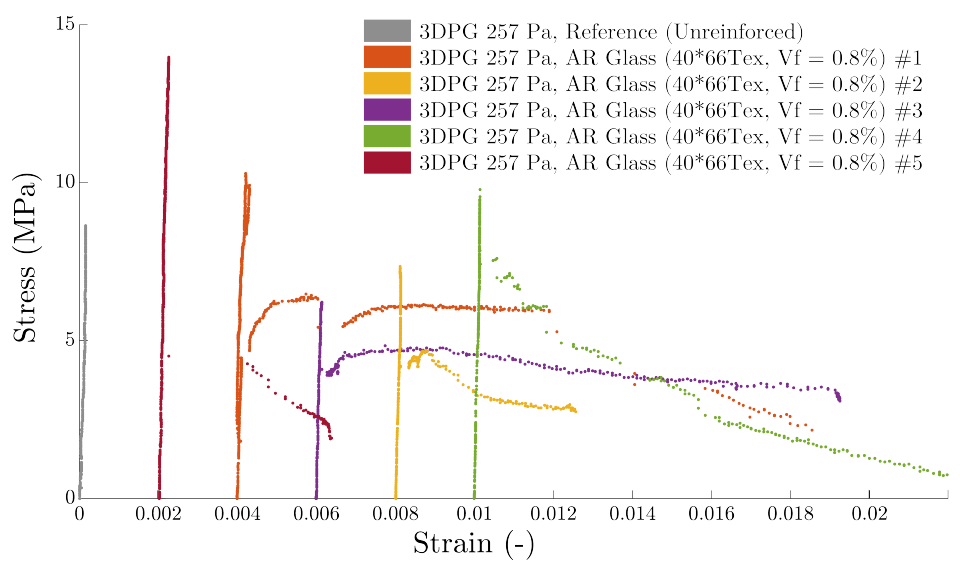

Figure 29: Stress-strain curves for high yield stress (256 Pa) EM specimens. Curves are offset for clarity.

In 14 the influence of this interface is discussed and it is shown a contrario that too strong interfaces may also decrease the ductility, by preventing decohesion mechanisms able to dissipate cracking energy. Consequently it is really important to understand and master these impregnation aspect. And the yield 


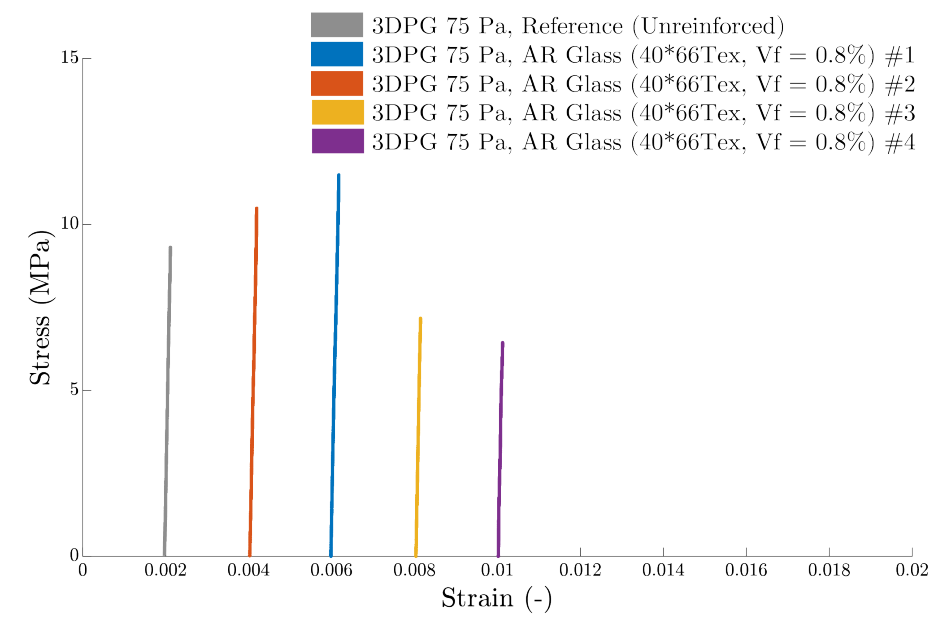

Figure 30: Stress-strain curves for low yield stress (75 Pa) EM specimens. Curves are offset for clarity.

stress of the matrix is proven here to be a keypoint.

Increasing reinforcement: by allowing up to 40 rovings, EM allows to formulate specimens with higher reinforcement rates than with FBP. Figure 31 shows the stress-strain curves of $6 \%$ reinforced specimens tested in direct tension. Those ${ }_{625}$ are formulated with the same strong printable matrix as FBP specimens (Lafarge $3 \mathrm{DPG}$ ) (Section 4.3.2). Specimens are tested after a complete 28-day curing (1 day in humid environment, 27 days immersed in water). The increase of strength (X3) is remarkable and promising for a real improvement of the performance of the printed material. The strain-hardening behaviour is typical ${ }_{630}$ of Strain-Hardening Cementitious Composites (SHCC) and very interesting to propose ductile concrete structures.The multicracking phenomenon which permits such performances is clearly visible with DIC (Digital Image Correlation) as shown in Figure 32 .

Using a weaker matrix Figure 33 concerns a previous preliminary investigation of moulded reinforced specimens and involving a more simple process than the EM described here. Those are 7-days-old specimens, thus having a weaker matrix (the cement has not reached its optimal performance). It shows the strong increase of resistance (up to $20 \mathrm{MPa}$ ) and ductility compared to the unreinforced reference sample. These results suggest that using a weak matrix allows high strength and multicracking without needing important reinforcement amounts (up to $\mathrm{Vf}=1.4 \%$ using 14 rovings). Such formulation seems achievable using FBP and will be explored in further works. 


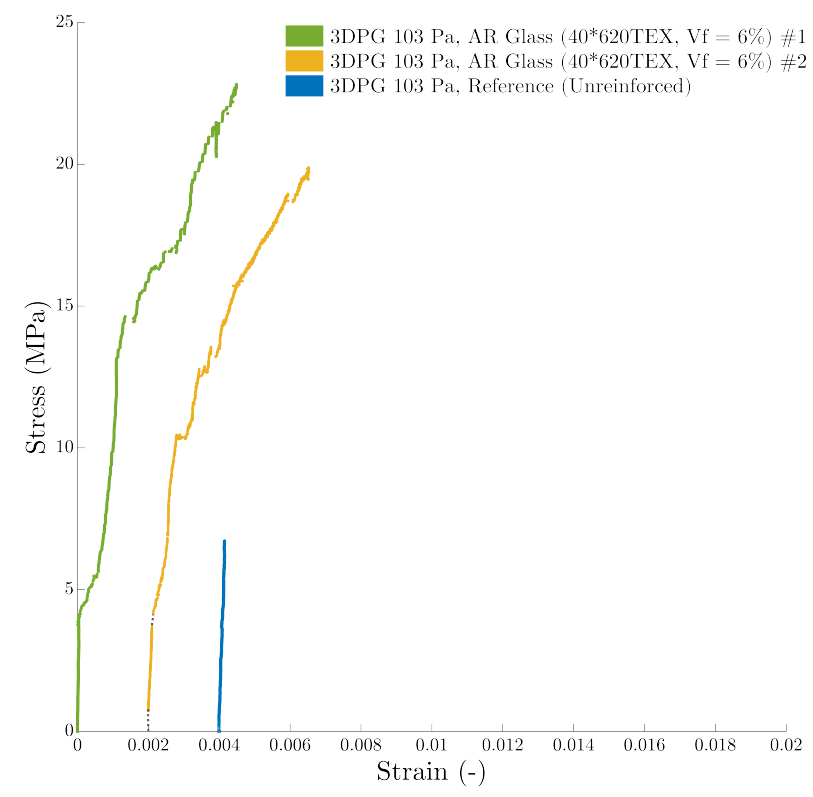

Figure 31: Stress-strain curves for EM tension specimens with highreinforcement ratio $(\mathrm{Vf}=6 \%)$ and tough matrix . Curves are offset for clarity.

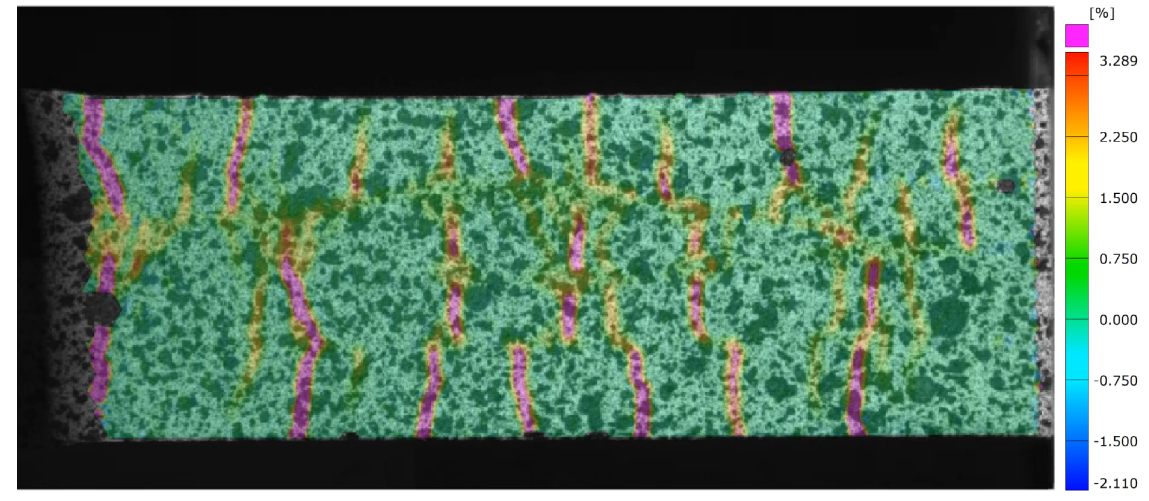

Figure 32: Strain digital image correlation for EM specimen with highreinforcement ratio and tough matrix during a tension test, showing multicracking. 


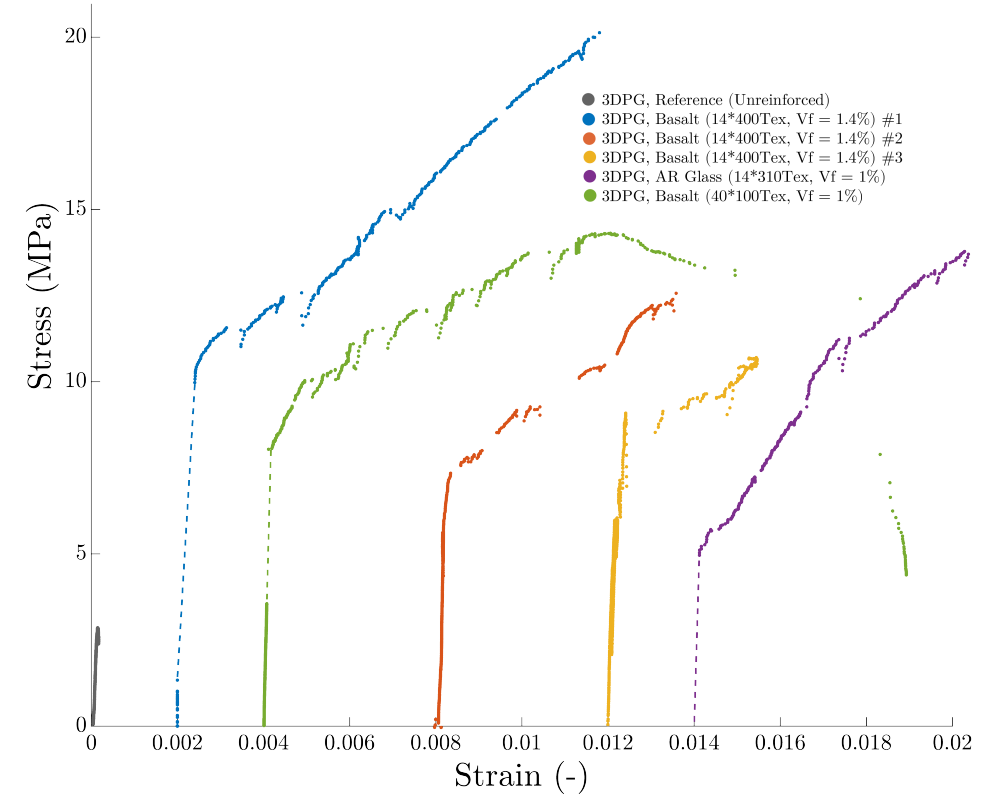

Figure 33: Stress-strain curves of 7 days specimens. Curves are offset for clarity.

\section{Conclusion and potential for new applications}

${ }_{645}$ First real-scale concrete realizations involving additive manufacturing have been achieved in the past decades. It seems impossible now that these new digital technologies will not be a part of the toolkit for tomorrow's building. One of the main gaps between experimentation and industry is probably that printed components are not reinforced, and do not yet comply with building standards or basic reliability principles. Consequently they are rarely used as critical loadbearing components. Actually, despite several attempts, no industrial solution for the reinforcement of the 3D printed components exists on-shelves. This article presents a solution for reinforcement of 3D printed structures. Inspired by the composite industry it is called FBP for flow-based pultrusion for additive manufacturing. A strict control of the geological behaviour of the cementitious matrix ensures the routing and impregnation of continuous rovings of thin fibres resulting to an Anisotropic Concrete. Homogeneously reinforced in a single direction, the material proposes enhanced strength and ductility. This paper describes the process, and first experimental achievements.

${ }_{660}$ Thanks to the possibility of a mastering of the time-dependent rheology of the mortar, first a good impregnation of rovings and then, a good mechanical behavior of the stacking of printed laces are achieved. Another point is that only the shear interaction between the concrete flow and the rovings ensures the pulling force on the rovings avoiding any external motorization and helping to a natural management of the fiber deposition. 
A prototype of a FBP printing device, up to 10 bobbins of glass and basalt fibers, permits a fiber ratio between $0.2 \%$ and $1 \%$. Increasing this ratio is easily possible using more bobbins and industrial developments.

The first experiments with FBP device highlight new possibilities offered by the anisotropic mortar at the fresh state: the consistency of the lace, even with few fibers, permits a really easy handling and avoids avalanche and slug effects during the printing. The quality of the printing could be improved even for worst situations (slopes, cantilever). Concerning the hardened state, the performance of the anisotropic concrete is also studied. 2 different devices are used, 675 the FBP prototype and a bench-top extruder called here Extrusion Moulding (EM), especially developed to push the limits prescribed by the FBP prototype which are a tough and brittle matrix (designed for 3D printing), and a fiber ratio up to $1 \%$. EM permits to investigate different cementitious matrix (weaker for instance), and higher fiber ratio, up to $6 \%$. Different specimens are fabricated, for direct tension and bending, and with different matrices, fibers, and fiber-ratio. All the tests, after be comforted that the 2 processes EM and FBP are comparable, highlight interesting results in term of pseudo strain-hardening (ductility) and even in term of strengthening of the mortar. The importance of both the fiber ratio and toughness of the matrix is highlighted and several 685 combinations are very promising, high fiber ratio embedded in strength matrix, or on the contrary, lower fiber ratio in a weaker matrix. The 2 routes are now investigated, meaning increasing the number of rovings with a second stage of bobbins, and trying weaker cementitious formulations we develop.

The perspectives are important. The high tensile strength of the fresh lace surely offers potential for new applications in concrete printing. In particular, although 3d printing is often presented as a technology that offers seemingly limitless formal possibilities without the need for any formwork, the printing of concrete structures as the corolla in Figure 34 without scaffolding remains an open research question [6] that a FBP fresh lace may answer. In this specific 695 case the hardened anisotropic concrete may also help to the structural performances, avoiding for instance the cracks in tensed rings. Another example is illustrated in the Figure 35. A prototype of a new building system generalizing both concrete printing and masonry principles is proposed (see [12, [11] for details). The continuous reinforcement provided by FBP should be highly suitable.

700 At fresh state, the reinforcement would help the fresh laces to accept inclined situations without irregularities nor avalanche effects. At hardened state, the reinforcement would be aligned with the tensile stresses of the truss. Finally, playing with anisotropy, struts and ties mechanics, is an opportunity to rethink ways of building with concrete.

\section{${ }_{705}$ Acknowledgment}

This work was made in the framework of Nicolas Ducoulombier and Leo Demont's PhD theses. Nicolas Ducoulombier's thesis has benefited from a French government grant managed by ANR within the frame of the national program 

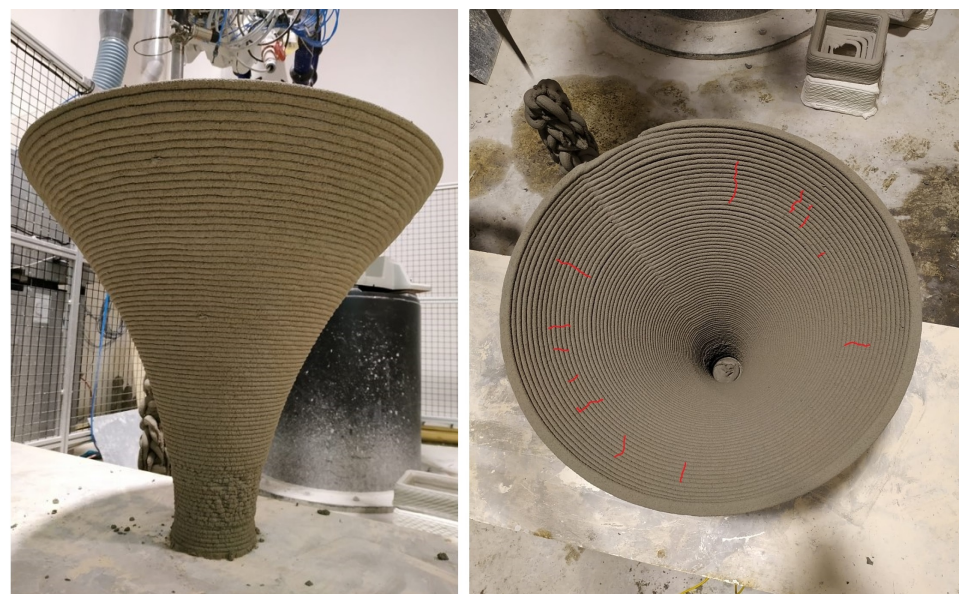

Figure 34: Corolla and cracking pattern (in red) in tensed rings

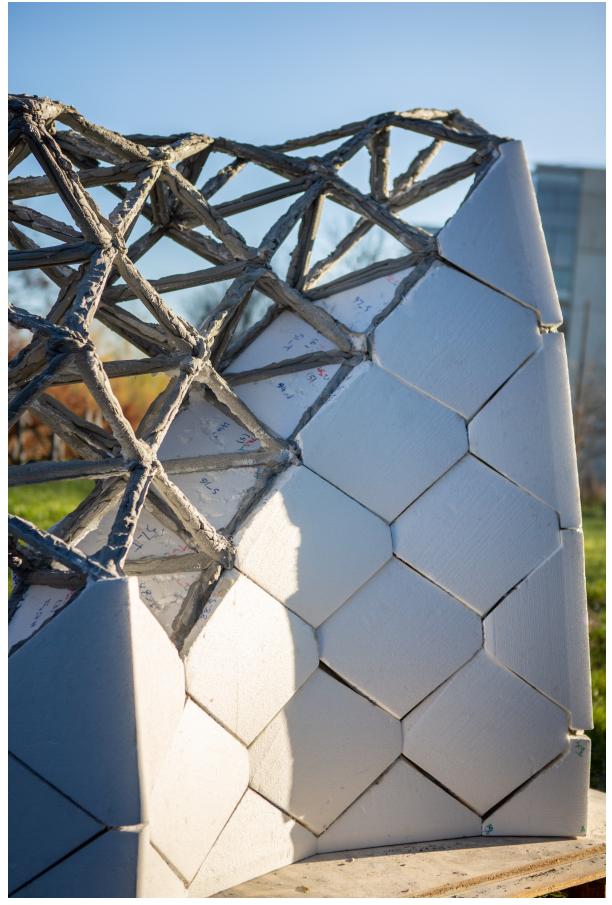

Figure 35: Space Truss Masonry Wall with Robotic Extrusion [11, 13. 
Investments for the Future ANR-11- LABX-022-01. Leo Demont's thesis is

funded by Ecole des Ponts ParisTech and Build'in, a technology platform of its Co-Innovation Lab. The authors also acknowledge the fruitful collaboration with XTreeE, technology provider of the extruder and HAL Robotics for joined software development for robotic control.

\section{References}

[10] L Demont, D Ducoulombier, R. Mesnil, and J-F. Caron. Flow-based pultrusion of continuous fibers for cement-based composite material and additive manufacturing: rheological and technological requirements. Composite Structures, page 113564, 2021.

[1] Eurocode 2-design of concrete structures: part 1-1 -general rules and rules for buildings. BSI, London, 2004.

[2] ACI ACI. 318-19. building code requirements for structural concrete, 2019.

[3] R. M. Andrew. Global co2 emissions from cement production. Earth Syst. Sci. Data, 10:195-217, 2018.

[4] Domenico Asprone, Costantino Menna, Freek P. Bos, Theo A. M. Salet, Jaime Mata-Falcón, and Walter Kaufmann. Rethinking reinforcement for digital fabrication with concrete. Cement and Concrete Research, 112:111121, October 2018.

[5] Freek P. Bos, Zeeshan Y. Ahmed, Evgeniy R. Jutinov, and Theo A. M. Salet. Experimental Exploration of Metal Cable as Reinforcement in 3D Printed Concrete. Materials (Basel, Switzerland), 10(11), November 2017.

[6] P. Carneau, R. Mesnil, N. Roussel, and O. Baverel. Additive manufacturing of cantilever - from masonry to concrete $3 \mathrm{~d}$ printing. Automation in Construction, 2020.

[7] Paul Carneau, Romain Mesnil, Nicolas Ducoulombier, Nicolas Roussel, and Olivier Baverel. Characterisation of the Layer Pressing Strategy for Concrete 3D Printing. In Freek P. Bos, Sandra S. Lucas, Rob J.M. Wolfs, and Theo A.M. Salet, editors, Second RILEM International Conference on Concrete and Digital Fabrication, RILEM Bookseries, pages 185-195, Cham, 2020. Springer International Publishing.

[8] Jean-François Caron and Nicolas Ducoulombier. Method and device for manufacturing an anisotropic concrete - wo2020249913/fr3097152,, 17 Dec 2020 .

[9] O Chaallal and B. Benmokrane. Fiber-reinforced plastic rebars for concrete applications composites. Part B: Engineering, 27(3-4):245-252, 1996. 
[11] R. Duballet, O. Baverel, and J. Dirrenberger. Space truss masonry walls with robotic mortar extrusion. Structures, 18:41-47, 2019.

[12] Romain Duballet. Systèmes Constructifs En Fabrication Additive de Matériaux Cimentaires. PhD thesis, September 2019.

[13] Romain Duballet, Romain Mesnil, Nicolas Ducoulombier, Paul Carneau, Leo Demont, Motamedi, Olivier Baverel, Jean-François Caron, and Justin Direnberger. Free deposition printing for space truss structures. In Second RILEM International Conference on Concrete and Digital Fabrication Digital Concrete 2020, 2020.

[14] N. Ducoulombier, C. Chateau, M. Bornert, J-F. Caron, P. Aimedieu, T. Weitkamp, J. Perrin, A. King, and M. Scheel. X-ray tomographic observations of microcracking patterns in fibre-reinforced mortar during tension stiffening tests. Strain, 2020.

[15] N. Ducoulombier, L Demont, C. Chateau, M. Bornert, and J.F Caron. Additive manufacturing of anisotropic concrete: a flow-based pultrusion of continuous fibers in a cementitious matrix. Procedia Manufacturing, 47:1070-1077, 2020.

[16] Nicolas Ducoulombier, Romain Mesnil, Paul Carneau, Léo Demont, Hela Bessaies-Bey, Jean-François Caron, and Nicolas Roussel. The "slugs-test" for extrusion-based additive manufacturing: Protocol, analysis and practical limits. Cement and Concrete Composites, 121:104074, 2021.

[17] Mariaenrica Frigione and Mariateresa Lettieri. Durability Issues and Challenges for Material Advancements in FRP Employed in the Construction Industry. Polymers, 10(3):247, March 2018.

[18] Nadja Gaudillière, Romain Duballet, C. Bouyssou, Alban Mallet, Philippe Roux, Mahriz Zakeri, and Justin Dirrenberger. Large-Scale Additive Manufacturing of Ultra-High-Performance Concrete of Integrated Formwork for Truss-Shaped Pillars. In Robotic Fabrication in Architecture, Art and Design 2018, pages 459-472. Springer International Publishing, August 2018.

[19] C. Gosselin, R Duballet, N. Roux, Ph.and Gaudillière, J Dirrenberger, and $\mathrm{Ph}$. Morel. Large-scale 3d printing of ultra-high performance concrete - a new processing route for architects and builders. Materials Design, 100:102-109, 2016.

[20] M Hambach and D Volkmer. Properties of 3d-printed fiber-reinforced portland cement paste. Cem. Concr. Compos., 79:62-70, 2017.

[21] B. Khoshnevis, D. Hwang, K-T Yao, and Z. Yah. Mega-scale fabrication by contour crafting. Int. J of Industrial and Systems Engineering, 60:301-320, 2006. 
[22] Victor C. Li and Hwai-Chung Wu. Conditions for Pseudo Strain-Hardening in Fiber Reinforced Brittle Matrix Composites. Applied Mechanics Reviews, 45(8):390-398, August 1992.

[23] S. Lim, R. A. Buswell, T. T. Le, S. A. Austin, A. G. F. Gibb, and T. Thorpe. Developments in construction-scale additive manufacturing processes. $A u$ tomation in Construction, 21:262-268, January 2012.

[24] E Lloret, A.R. Shahab, M. Linus, R.J. Flatt, F. Gramazio, M. Kohler, and S. Langenberg. Complex concrete structures: Merging existing casting techniques with digital fabrication. Computer-Aided Design, 60:40-49, 2015 .

[25] Ryosuke Matsuzaki, Masahito Ueda, Masaki Namiki, Tae-Kun Jeong, Hirosuke Asahara, Keisuke Horiguchi, Taishi Nakamura, Akira Todoroki, and Yoshiyasu Hirano. Three-dimensional printing of continuous-fiber composites by in-nozzle impregnation. Scientific reports, 6:23058, 2016.

[26] Viktor Mechtcherine, Richard Buswell, Harald Kloft, Freek P. Bos, Norman Hack, Rob Wolfs, Jay Sanjayan, Behzad Nematollahi, Egor Ivaniuk, and Tobias Neef. Integrating reinforcement in digital fabrication with concrete: A review and classification framework. Cement and Concrete Composites, 119:103964, 2021.

[27] Viktor Mechtcherine, Albert Michael, Marco Liebscher, and Tobias Schmeier. Extrusion-based additive manufacturing with carbon reinforced concrete: Concept and feasibility study. Materials, 13(11):2568, 2020.

[28] Philippe Monnot, Jonathan Lévesque, and Louis Laberge Lebel. Automated braiding of a complex aircraft fuselage frame using a non-circular braiding model. Composites Part A: Applied Science and Manufacturing, 102:48-63, November 2017.

[29] A. Nanni. Flexural behavior and design of rc members using frp reinforcement. Journal of structural engineering, 119(11):3344-3359, 1993.

[30] B Panda, P Chandra, and M Jen Tan. Anisotropic mechanical performance of $3 \mathrm{~d}$ printed fiber reinforced sustainable construction material. Material Letters., 209:146-149, 2017.

[31] C Pascal, P Rossi, and I. Schaller. Can steel fibers replace transverse reinforcements in reinforced concrete beams? Materials Journal, 94(5):341$354,1996$.

[32] Zhengyue Ren and Lijiu Wang. Applied research of light steel rib-concrete with dipy construction formwork system. Proceedings of the Fourth International Conference on Advances in Steel Structures, I:665-670, 2005.

[33] N. Roussel. A thixotropy model for fresh fluid concretes: Theory, validation and applications. Cement and Concrete Research, 36:1797-806, 2016. 
[34] N. Roussel and Philippe Coussot. "fifty-cent rheometer" for yield stress measurements: From slump to spreading flow. Journal of Rheology, 49, 05 2005 .

825 [35] Nicolas P. Roussel. Rheological requirements for printable concretes. 2018.

[36] Daniel Andrés Salas, Angel Diego Ramirez, Carlos Raúl Rodríguez, Daniel Marx Petroche, Andrea Jael Boero, and Jorge Duque-Rivera. Environmental impacts, life cycle assessment and potential improvement measures for cement production: A literature review. Journal of Cleaner Production, 113:114-122, February 2016.

[37] Alexander Scholzen, Rostislav Chudoba, and Josef Hegger. Thin-walled shell structures made of textile-reinforced concrete. Structural Concrete, 16(1):106-114, 2015.

[38] SF3DR. 3 dr @ structural formwork, 1999.

835 [39] Gieljan Vantyghem, Wouter De Corte, Emad Shakour, and Oded Amir. 3D printing of a post-tensioned concrete girder designed by topology optimization. Automation in Construction, 112:103084, April 2020.

[40] K. Wille, S. El-Tawil, and A. E. Naaman. Properties of strain hardening ultra high performance fiber reinforced concrete (UHP-FRC) under direct tensile loading. Cement and Concrete Composites, 48:53-66, April 2014.

[41] Ernst Worrell, Lynn Price, Nathan Martin, Chris Hendriks, and Leticia Ozawa Meida. Carbon dioxide emissions from the global cement industry. Annual Review of Energy and the Environment, 26(1):303-329, 2001. 